\title{
Nuevos datos sobre el diseño urbano de Toletum: las cloacas de la Bajada del Barco
}

\author{
Arturo RuIz TABOADA \\ Universidad Complutense de Madrid \\ arruiz01@ucm.es \\ Sandra AzCÁRraga CÁmARA \\ sandra.azcarraga@gmail.com
}

Doctora en Prehistoria y Arqueología por la Universidad Autonoma de Madrid

Recibido: 8 de mayo de 2015

Aceptado: 1 de febrero de 2016

\begin{abstract}
RESUMEN
El artículo da cuenta de la complejidad de desarrollar estudios integrales en ciudades históricas permanentemente habitadas, a través de los resultados de una reciente excavación de la confluencia de dos cloacas romanas y su contextualización con otros hallazgos de similares características en Toledo. La gran cantidad de restos arqueológicos de Toletum descubiertos en los últimos años contrasta con la escasez de trabajos publicados, lo que sigue condicionando la imagen académica establecida desde hace décadas para la ciudad antigua. Aunque aún queda un largo camino por recorrer, los últimos hallazgos han permitido matizar aspectos sobre su diseño urbano y evolución desde la II Edad del Hierro hasta el final de la época romana.
\end{abstract}

Palabras clave: Toletum/Toledo. Urbanismo romano. Cloacas.

\section{New Evidences on the Toletum Urban Design: The Bajada del Barco Sewers}

\begin{abstract}
The recent discovery and excavation of two Roman sewers junction in one of the main Toledo arteries has highlighted the need to reflect on the academic image of Roman Toledo developed in the last few decades. Due to the lack of published works, any attempt to develop theories about its urban plan is rather daring. Nevertheless, the latest findings have allowed for the explanation of part of its layout and evolution from the Second Iron Age to the Roman period. Consequently, these two sewers from two different periods and with different orientation give information about the road and water networks they belong to, as well as illustrating the complexity of this type of studies in permanently inhabited cities, and pointing out the long way still ahead for their complete understanding.
\end{abstract}

Keywords: Toletum/Toledo. Roman urbanism. Sewers.

Sumario: 1. Introducción. 2. Arqueología y fuentes clásicas: el oppidum prerromano. 3. Arqueología e historiografía: la estructuración de la ciudad romana. 4. Las cloacas de la Bajada del Barco. 5. Consideraciones en torno a la distribución interna de la ciudad. 6. Conclusiones. 


\section{Introducción}

El conocimiento actual de Toletum, tanto prerromano como romano, dista mucho de hallarse en un estado aceptable, siendo muchas las lagunas existentes. Como destacan diversos investigadores, a pesar de las numerosas intervenciones arqueológicas realizadas en la ciudad (motivadas principalmente por la gestión urbanística) son muy escasos los datos arqueológicos disponibles, sobre todo los referentes a la cultura material y, con ello, el conocimiento de la romanización es aún muy parcial. ${ }^{1}$

El debate sobre el tipo de diseño urbano de la ciudad lo inicia en la década de los noventa del s. XX Rubio Rivera, ${ }^{2}$ al proponer un modelo ortogonal para la práctica totalidad de la superficie de Toletum, con desarrollo norte-sur y este-oeste, basado tanto en los escasos restos materiales publicados como en el trazado de muchas de las calles medievales actualmente conservadas. Recientemente Blázquez, ${ }^{3}$ asumiendo las conclusiones de otros autores a este respecto, defiende la idea de una trama urbana heterogénea adaptada a la especial topografía más que una ortogonalidad convencional. Además, se limita a recopilar la información sobre la ciudad romana centrándose en los restos mejor conocidos como edificios lúdicos o el sistema hidráulico, que ya fueron agrupados en su día en una monografía editada por el Consorcio de la Ciudad de Toledo. ${ }^{4}$ Más novedoso es el catálogo epigráfico de la provincia de Toledo, donde el apartado referido a la ciudad recoge diversas piezas inéditas. ${ }^{5}$ Como veremos, el resto de los trabajos publicados tampoco analizan los múltiples hallazgos toledanos en su conjunto, limitándose a hacer un inventario de los mismos sin ninguna conexión entre ellos, lo que nos devuelve a las visiones clásicas asumidas por la investigación tradicional.

El presente artículo pretende reconducir este debate mediante el planteamiento de nuevas hipótesis destinadas a analizar tanto los datos conocidos, plasmados en el plano de hallazgos elaborado por el Consorcio o en diferentes publicaciones parciales más recientes, como los que aporta el estudio pormenorizado de las cloacas de la Bajada del Barco y su relación con el resto de la ciudad. ${ }^{6}$ De este modo, teniendo en cuenta la heterogeneidad de la que hablan investigadores como Blázquez y Schattner, se propone la posible existencia de una trama ortogonal al menos en el sector central del cerro, condicionada y adaptada a su especial orografía, aunque con diferente orientación a la propuesta en su día por Rubio Rivera. ${ }^{7}$

El problema de este tipo de estudios radica en la dificultad de establecer la diacronía o sincronía de los restos, con lo que el planteamiento de hipótesis tendrá en cuenta la posibilidad de tal interferencia. Para ello, se va a examinar de forma conjunta tanto

1 SÁnchez-Palencia - SÁinz Pascual 1988; Alvar - Mangas 1990; Andreu 2008; Nogales - Acuña 2013.

2 Rubio Rivera 1997.

3 Blázquez 2012, 60.

4 Rosado Artalejo 2005.

5 Abascal Palazón - Alföldy 2015, 253-282.

6 Agradecemos a Thomas Schattner los comentarios hechos al borrador de este artículo, así como al comité de redacción de la revista las gestiones y tiempo empleados en su mejora.

7 Rubio Rivera 1997, 363. 
el contexto arqueológico de los materiales publicados y los nuevos documentados, como aquellos aspectos recogidos por las fuentes antiguas y la historiografía tradicional que hablen de la evolución de la ciudad, comenzando con una puesta al día razonada, contextualizada y con propuestas concretas del oppidum carpetano (Fig. 1).

Figura 1. Mapa de situación con las principales ciudades mencionadas en el texto.

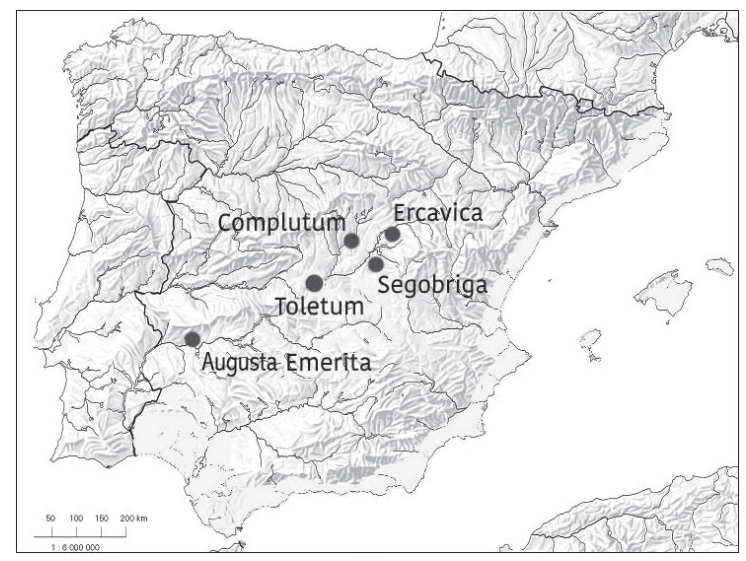

\section{Arqueología y fuentes clásicas: el oppidum prerromano}

El asentamiento localizado en la parte superior del cerro contaba con una situación geográfica inmejorable de cara a sus defensas, aunque su distribución interior debía de estar condicionada por las escorrentías naturales del terreno y el relieve interno. El peñón toledano limita al este, oeste y sur con el río Tajo, con un frente norte abierto a las vegas, fácilmente defendible y un vado natural (Fig. 2).

En la actualidad son muy escasos los restos arqueológicos conocidos del Toledo prerromano. Casi todos se corresponden con materiales cerámicos y la mayoría aparecen en posición secundaria. Los datos más recientes proceden de la memoria de excavación de la Catedral, aunque su publicación como los propios autores admiten, ofrece sólo "la documentación de la excavación sin un ulterior estudio". ${ }^{8}$ En esta intervención cabe destacar la aparición en distintas zonas del claustro, de niveles carpetanos en su mayoría asociados con materiales cerámicos pero no con estructuras. Respecto a estas últimas, únicamente se menciona una hilada circular de piedras, un muro recto de adobes con un posible hogar rectangular y un pequeño horno circular, en base a lo cual se propone la existencia de un poblado de la Segunda Edad del Hierro de cierta envergadura ${ }^{9}$ (Fig. 2-13). Otros exiguos restos asociados a posibles estructuras carpetanas se corresponden con un silo hallado en la calle Nueva, un muro de sillares de granito en la calle Santa Fe y una posible estructura habitacional

8 Almagro-Gorbea 2011, 13.

9 IBID. 241. 
en el Corralillo de San Miguel asociada a abundantes cerámicas pintadas a bandas, círculos concéntricos, estampilladas o jaspeadas. ${ }^{10}$ Llama la atención la ubicación de las estructuras documentadas, todas ellas en la zona noreste del peñón toledano, que se corresponde con la explanada norte del Alcázar y el entorno de la Catedral y comprende la colina más alta de Toledo (548 m), junto a Zocodover, separada del resto del peñón por dos escorrentías. Este entorno además constituye uno de los espacios más amplios y nivelados, que no por casualidad es la zona desde la que mejor se controla el vado del Tajo a esa altura de su curso (Fig. 2). Fuera de esta superficie de unas 25 ha no se han localizado o publicado, por el momento, estructuras asociadas a estratos carpetanos y los restos materiales documentados aparecen en su mayoría fuera de su contexto original o bien se trata de hallazgos aislados como el del Convento de Santa $\mathrm{Fe}$, que quizá podría tratarse de un basurero extramuros del oppidum ${ }^{11}$ (Fig. 2-13).

Figura 2. Topografía del peñón toledano ${ }^{12}$ con la ubicación de los hallazgos prerromanos, y propuesta de la extensión y localización del oppidum y zona óptima para una posible localización de un campamento romano: 1. Nuncio Viejo 3; 2 . Amador de los Ríos 5; 3. Santa María la Blanca; 4. C/ Ciudad; 5. Garcilaso de la Vega 3; 6. San Pedro Mártir; 7. Convento Santa Fe; 8. Bajada de Infantes 16; 9. Calle Nueva 7, 9 y 11; 10. C/ Santa Fe; 11. Corralillo San Miguel;

12. Cerro del Bu; 13. Catedral de Santa María; 14. Alcázar; 15. Palacio de Lorenzana.

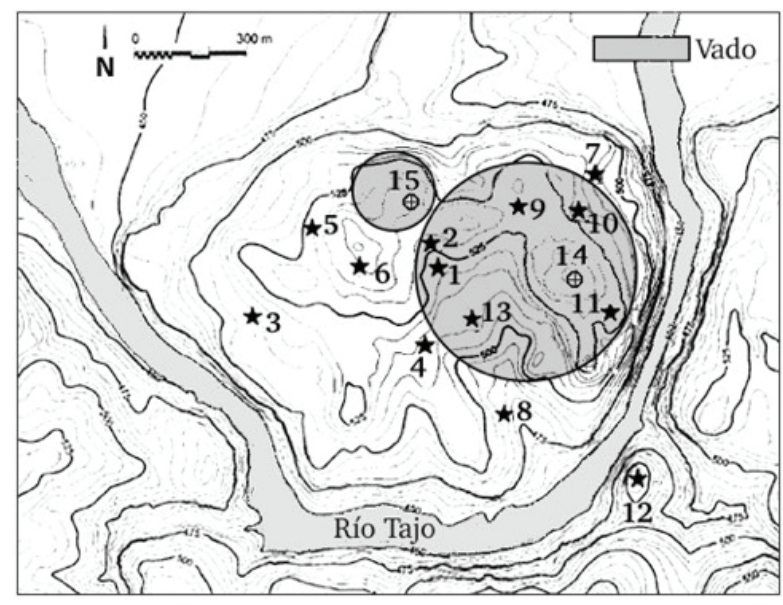

Gracias al avance en la investigación sobre la Carpetania, hoy en día no se concibe la existencia de grandes oppida de más de 25 ha en la zona, defendidos hace años por diversos investigadores que otorgaban una superficie de más de 100 ha a Complutum y de 40 a Toletum. ${ }^{13}$ En el caso del primero de los oppida mencionados se ha propuesto recientemente, en base a varias campañas de prospección, la localización

\footnotetext{
10 Fernández del Cerro - Barrio Aldea 2002, 362-365.

11 IBID.

12 Fernández del Cerro - Barrio Aldea 2002, 363, Figura 1, modificada.

13 Almagro-Gorbea 1994, 34; Almagro-Gorbea - Dávila 1995, 221.
} 
del asentamiento prerromano en una zona concreta del cerro de San Juan del Viso (Villalbilla, Madrid) y en una superficie de unas 6-8 ha, siendo la meseta del cerro mucho mayor. ${ }^{14}$ Gracias al análisis de la fotografía aérea podemos considerar que la ciudad romana se extendió ex novo frente a dicho oppidum, en una superficie de al menos 30 ha. En este sentido, cabría preguntarse si estamos ante un caso similar en Toletum, donde el oppidum prerromano se pudo desarrollar en esa zona concreta de 25 ha citada anteriormente desde la que se controlaba el vado, con un tamaño más en consonancia con el de los oppida peninsulares, y con una amplia superficie próxima en la que los romanos pudieran desarrollar su urbanismo. Esta hipótesis de ocupación parcial del gran peñón toledano en época prerromana estaría en consonancia con la de otros autores como Montero o Porres Martín-Cleto ${ }^{15}$ y discreparía con la propuesta de Almagro-Gorbea que concibe una acrópolis y una ocupación generalizada y conectada con varios caminos. ${ }^{16}$

De acuerdo con esta propuesta podrían reinterpretarse las fuentes, que al contrario de lo que sucede con otros oppida, destacan el papel de Toletum prerromano en el proceso de conquista de la Submeseta Sur. Livio hace referencia al originario oppidum desde los inicios de la penetración romana en el interior peninsular a principios del s. II a.C., lo que por sí sólo es una muestra de la relevancia del asentamiento, calificándolo de "parva urbs, sed loco munito". ${ }^{17} \mathrm{El}$ hecho de considerarla una ciudad pequeña hace difícil pensar en una superficie amplia, que a pesar de extenderse en un terreno escarpado bien pudo necesitar la fortificación de algunas zonas, como parece indicar la cita. En este sentido, Porres ${ }^{18}$ propone la existencia de una posible fortificación en la calle Santa Fe, asociando el muro allí documentado con dicho fin. Este investigador considera, sin embargo, que el poblamiento se extendería en las cinco colinas centrales más elevadas, en una superficie de unas 24 ha. ${ }^{19}$ Por desgracia, aún no contamos con pruebas definitivas ni de la extensión exacta del oppidum ni de su fortificación, que pudiera situarse en el entorno del Alcázar (Fig. 2-14). Por si esto fuera poco, no ayudan actuaciones como el vaciado arqueológico de la explanada norte del Alcázar entre 1999 y 2005, con motivo de las obras de ampliación del Museo del Ejército que, hasta el momento, sólo ha generado una publicación genérica de lo que allí había. ${ }^{20}$

Otra hipótesis posible pero que, hoy por hoy, carece de evidencias arqueológicas, sería la del origen de la ciudad romana en un campamento, de modo similar al que se produce en muchas ciudades hispanas y parece tener lugar más tardíamente en la también carpetana Complutum. En este caso, basándonos en la topografía del peñón, el lugar más favorable para el asentamiento de un campamento romano, por ser además el más elevado después de la colina del Alcázar, sería el que en la actualidad alberga edificios como el palacio Lorenzana o el convento de los Jesuitas, sede de

14 Azcárraga Cámara - Ruiz Taboada 2012-2013; ID. 2014; Azcárraga Cámara 2014; EaD. 2015.

15 Montero 1988, 230-132; Porres Martín-Cleto 1989.

16 Almagro-Gorbea 2011, 242 y Lám. 187.

17 Liv. XXXV. 22, 25.

18 Porres Martín-Cleto 1992.

19 Porres Martín-Cleto 1989.

20 Zozaya Stabel-Hansen et alii 2005. 
la Delegación de Hacienda (Fig. 2-15). Su existencia se podría justificar tanto por el sitio que según las fuentes sufrió el oppidum, como por el posible acuartelamiento de invierno de las tropas para el desarrollo de las guerras celtibéricas y lusitanas o por el asentamiento posterior de legiones.

Teniendo en cuenta este análisis, los datos arqueológicos apuntarían a que el urbanismo romano desarrollado más allá del oppidum fuera totalmente ex novo, aunque el antiguo emplazamiento también se romanizara y acabara adaptándose al modelo constructivo romano. Cómo se urbanizó es una cuestión que ha generado un debate todavía en vigor. Por una parte, contamos con una orografía difícilmente comparable con aquella de otras ciudades localizadas en llano como Augusta Emerita, Corduba o Complutum, ${ }^{21}$ lo que dificulta cualquier propuesta de diseño. ${ }^{22}$ Por otra, un análisis detallado de la plataforma superior del cerro sugiere que, al menos en el sector más llano, pudo desarrollarse un cierto urbanismo ortogonal, a partir de la nivelación programada de su superficie, sirviéndose de las principales escorrentías como ejes urbanos. Sin embargo, es su ubicación en altura lo que la relaciona con ciudades de orografía parecida como Segobriga, Ercavica o Munigua. ${ }^{23}$

Volviendo a las fuentes, merece la pena recordar los pasajes relacionados con Toletum y detenernos en algunos puntos. En primer lugar, no es de extrañar su aparición en ellas, ya que estratégicamente era una de las conquistas necesarias para Roma de cara al control del Tajo, lugar de paso y primordial en las comunicaciones de la Meseta con el sur. Por su parte, Livio ${ }^{24}$ narra cómo en el 193 a.C. Fulvio Nobilior, pretor de la Ulterior, alcanza la línea del Tajo, pasando por los oppida oretanos Nobila y Cusibi llegando hasta Toletum, donde vencería a una coalición de vetones, vacceos y celtíberos (que habían acudido en su ayuda) y apresaría al rey Hilerno. $\mathrm{Al}$ año siguiente, ${ }^{25}$ prorrogado el mando de los dos pretores de la Citerior y de la Ulterior, Nobilior anexiona Toletum sitiándola, a pesar de la ayuda de los vetones. ${ }^{26}$ La necesidad de tácticas de sitio se relaciona con la fortificación natural y/o artificial del oppidum e implicaría, posiblemente, la existencia de uno o varios campamentos en el entorno. El apoyo de los pueblos de alrededor a Toletum se ha interpretado por algunos autores como la reacción ante el temor de que los romanos controlaran el valle del Tajo haciendo peligrar el aprovechamiento mancomunado de los recursos naturales de ambas vertientes de los Carpetana Luga ${ }^{27}$ En nuestra opinión, el hecho de que Livio cuente cómo todos los pueblos de alrededor acuden en ayuda de Toletum puede interpretarse de dos formas. Por un lado, le serviría a Livio para destacar la superioridad romana contra un gran número de enemigos, en la línea general de su obra. Por otro, este apoyo, de ser tal cual lo narra Livio, aparte de mostrar el miedo de los pueblos de alrededor a perder la explotación de sus recursos y su propia indepen-

21 Cf. Mateos Cruz 2001; Velázquez Jiménez 1998; León Alonso et alii 1996; Stylow 1990; Ruiz TABOADA - AZCÁRRAGa CÁmARA 2014.

22 SChatTNer 2009; BLÁzquez 2012.

23 Cf. Almagro-Gorbea - Lorrio 2006-2007; Rubio Rivera 2013; Schattner 2003, respectivamente.

24 Liv. XXXV. 7, 6.

25 Liv. XXXV. 22, 5.

26 Carrasco Serrano 1996-1997, 746.

27 SÁnchez Moreno - Gómez Pantoja 2008, 330. 
dencia, indicaría la importancia de Toletum en el entorno y el funcionamiento de unas redes políticas ya consolidadas. Llama la atención el hecho de que se mencione a un rey, ${ }^{28}$ el único citado por las fuentes en el territorio carpetano, y que podría ser el jefe de esa coalición de vacceos, vetones y celtíberos. Sin embargo, no se precisa su procedencia, por lo que realmente no podemos saber si era el "rey" de Toletum, de alguno de los pueblos que acudió en su ayuda, o simplemente un caudillo elegido en ese enfrentamiento. Destaca también en este pasaje el hecho de que acuden en ayuda del oppidum celtiberos, vetones y vacceos, pero no se nombra a los carpetanos. Esta falta de mención expresa se puede interpretar simplemente como una evidencia que Livio no consideró oportuno destacar, o quizá que siendo Toletum la ciudad más importante de la Carpetania, el resto de poblados o bien habían sido vencidos con anterioridad y/o carecían de la suficiente entidad y capacidad organizativa para socorrerla. ${ }^{29}$

La siguiente referencia a Toletum en las fuentes se produce de manera indirecta, cuando Livio ${ }^{30}$ narra cómo hacia el 186-185 a.C. los pretores C. Calpurnio Pisón, de la Ulterior y L. Quincio Crispino, de la Citerior, llevaron a cabo diversas campañas en la Carpetania para fijar la frontera norte de la Ulterior en la línea del Tajo, relatando varios enfrentamientos cerca de Dipo y Toletum. En esta ocasión, el mejor conocimiento del terreno da la victoria a celtíberos y lusitanos. Tras estos acontecimientos ambos pretores contraatacaron y causaron un gran número de bajas entre el ejército indígena. ${ }^{31} \mathrm{Si}$ atendemos a la lectura tradicional, resulta controvertido el término "celtíberos", ya que no se tiene claro si con él Livio se refería a los carpetanos, dada la ubicación de las ciudades de Dipo y Toletum ${ }^{32}$ o más bien a una lucha de los celtíberos fuera de su territorio. ${ }^{33}$ Lo que sí resulta evidente es que Livio no realiza el mismo tratamiento con todas las poblaciones indígenas, ya que menciona por separado tanto a olcades, vetones y oretanos como a celtíberos. ${ }^{34}$ Es probable que si no usa el término "carpetanos" se deba o bien al hecho de que éstos no estuvieran implicados en el conflicto (lo que no sería de extrañar si tenemos en cuenta que Toletum fue reducido unos años antes), o quizá que en el momento en el que Livio escribe el término "carpetano" ya careciera de significado debido a la "romanización" de sus habitantes y utilizara genéricamente el término "celtíbero" para referirse a los indígenas del interior peninsular.

Sea como fuere, esta derrota no debió ser tan grande ya que en el 181 a.C. cuenta de nuevo Livio que el gobernador Fulvio Flaco tuvo que enfrentarse otra vez a los "celtíberos". En esta ocasión coloca su campamento cerca de Aebura, donde mantiene una lucha con aquellos, tomándola finalmente. ${ }^{35}$ Ahora Livio especifica el asedio

28 Liv. XXXV. 7, 6: maiores gestae res a M. Fulvio. is apud Toletum oppidum cum Vaccaeis Vectonibusque et Celtiberis signis collatis dimicauit. exercitum earum gentium fudit fugauitque, regem Hilernum vivum cepit.

29 AzCÁRraga CÁMARA 2015.

30 Liv. XXXIX. 30, 1.

31 Liv. XXXIX. 31, 1.

32 García y Bellido 2004, 32; Gozalbes Cravioto 2004, 105.

33 González-Conde 1987, 29; Urbina 1998, 190.

34 Abascal - GonZÁlez-Conde 2007, 293.

35 Liv. XL. 30, 1-3; Frontin., Strat. 11. 5, 8; App., Iber. 52; D. S. XXIX. 28. 
del oppidum carpetano de Aebura, ${ }^{36}$ por lo que, en esta ocasión, quizá con el término "celtíberos" se esté refiriendo a "carpetanos" o simplemente se refiera a los celtíberos que les ayudaron. Tras estos acontecimientos, según Livio, ${ }^{37}$ el ejército romano atraviesa Carpetania desde Aebura a Contrebia, ciudad que resulta sitiada, rindiéndose ante la imposibilidad de los celtíberos de prestarle la ayuda solicitada. Atendiendo a estos datos debemos considerar que en torno al 180 a.C. Toletum y la Carpetania ya estaban controladas por Roma y en el 151 a.C. incluso el territorio es defendido contra los vacceos con la excusa de trasladar allí la guerra. ${ }^{38} \mathrm{La}$ Carpetania se convierte de este modo en un lugar estratégico para la conquista del resto de la Península, lugar en el que se ubicarían los campamentos de invierno de las legiones durante las guerras lusitanas y celtibéricas.

Otra referencia a Toletum en las fuentes es la de Plinio en su Historia Natural, donde la menciona como ciudad estipendiaria ${ }^{39}$ en el momento de publicar su obra hacia el 77 d.C. Esta fecha ha generado un debate acerca de la actualización de los datos antes de la publicación de la obra, puesto que Plinio aporta un listado de ciudades estipendiarias que en su mayoría ya debían ser municipios en ese momento. La evidente desactualización de los datos es un hecho comúnmente admitido, ${ }^{40}$ aunque con algunas opiniones en contra. ${ }^{41}$ En este sentido, debemos destacar que la teoría más aceptada en la actualidad es la de la municipalización augustea de Toletum, ${ }^{42}$ de igual modo que parece suceder en otras ciudades de la Submeseta Sur como Segobriga ${ }^{43}$ y Ercavica. ${ }^{44}$

Por otro lado, la revisión de los manuscritos más antiguos de los textos plinianos realizada por Capalvo le lleva a proponer una nueva lectura de este pasaje que nombra las localidades pertenecientes al Conventus Carthaginiensis. Tradicionalmente se ha relacionado "caput celtiberiae" con Segobriga y se ha asumido que Toletum era también la "capital" de la Carpetania, siendo ésta la interpretación más extendida hoy en día. Sin embargo, para Capalvo, son los oretanos los que deberían ser considerados "cabeza" de la Celtiberia, Segobriga se consideraría carpetana y Toletum quedaría sin definir en el texto pliniano, ni como celtíbera ni como carpetana ${ }^{45}$ Por último, contamos con algunas escuetas referencias a Toletum, como la de Ptolomeo que en su Geografía ${ }^{46}$ lo incluye entre los dieciocho oppida carpetanos o la del poeta Gattio (s. I d.C.) que destaca los cuchillos de esta localidad. ${ }^{47}$

\footnotetext{
36 Liv. XL. 30, 3: principio ueris exercitum in Carpetaniam duxit et castra locavit ad oppidum Aeburam medico praesidio in urbe posito.

37 Liv. XL. 33, 1.

38 App., Iber. 50-52.

39 Nat. III, 25.

40 Mangas 1995, 76; GonzÁlez-Conde 1985, 136; EAD. 1987, 57, 94-95; García y Bellido 1977, 79, 101.

41 CANTO 1996.

42 Plácido et alii 1992, 363; Mangas 2012, 214-217.

43 Almagro-Gorbea - Lorrio 2006-2007.

44 Rubio Rivera 2013.

45 Capalvo 1996, 63-64.

46 Ptol. II. 6, 57N.

47 Cynegetica, V, 341.
} 


\section{Arqueología e historiografía: la estructuración de la ciudad romana}

Como ocurría con el asentamiento carpetano, carecemos de datos definitivos para fechar el inicio de la primitiva ocupación romana, pero sabemos que ya desde mediados del s. II a.C. el territorio está pacificado y quizá, como pudo ocurrir en otros lugares, el urbanismo se originara en la existencia previa de un campamento. En cualquier caso, la presencia de una ceca que acuña a finales de época republicana (sin que exista un consenso al respecto, aunque se podría pensar en gran parte del s. I a.C.) responde al reconocimiento de Roma a la ciudad. ${ }^{48}$ Los materiales más antiguos documentados en excavación, aunque descontextualizados, son dos fragmentos de "campaniense B" (Lamb. 7 y Lamb. 5) hallados en el Circo. ${ }^{49}$ Sin embargo, los restos constructivos romanos más antiguos localizados por el momento pertenecen a la época de Tiberio, en el segundo cuarto del s. I d.C. y se corresponden con grandes muros de hormigón asociados a la reestructuración de un sector residencial en la calle Nuncio Viejo, $3 .^{50}$ A estos datos debemos añadir la reciente datación y propuesta de ubicación de Nogales y Acuña acerca de la estatua togada de la calle de la Plata, fechada entre Tiberio y Claudio y asociada con dos muros de sillares de granito, conjunto interpretado como integrante del foro de la ciudad, ${ }^{51}$ aunque otros autores lo sitúan en el entorno de la Catedral y le otorgan una cronología Flavia. ${ }^{52}$

Con respecto los límites o pomerium, las únicas evidencias arqueológicas de muralla las encontramos en el entorno de la iglesia del Cristo de la Luz. Los sondeos llevados a cabo tanto en el huerto de Carmelitas Descalzas como bajo la puerta del Sol han despejado alguna de las incógnitas sobre el recinto amurallado de esta época. Mientras que los hallazgos en el primero se limitan a la documentación de una serie de tramos de muralla a base de sillares, y a noticias que hablan de la existencia de un cubillo y una cloaca, ${ }^{53}$ una reciente intervención en la puerta del Sol ha permitido contextualizar arqueológicamente dicha muralla. ${ }^{54}$ Durante la rehabilitación de esta puerta, en uno de los sondeos arqueológicos localizados en su fachada oriental, apareció la traza de una torre circular de 5,60 m de diámetro, en fábrica de sillar dispuesta en dos hiladas con talla ligeramente curva. El hallazgo se pudo contextualizar arqueológicamente gracias a la excavación de un vertedero al que estaba asociado. La formación de estos depósitos es posterior a la torre y su cerámica se ha fechado en el tercer cuarto del s. I d.C., con algunos fragmentos de época Julio-Claudia, como TSI y TSG y otros atribuibles a la segunda mitad de siglo, como TSH y algunas paredes finas y Meseta Sur. ${ }^{55}$ Según estos autores, el inicio del rodadero se remontaría a época neroniana a partir de los años finales de la década de los 70, lo que sugiere que la torre debió construirse con anterioridad a esta época.

48 Mangas 2012, 214-215.

49 Mena 1988, 30.

50 Aranda Alonso et alii 1997, 59.

51 Nogales - ACUÑa 2013.

52 Almagro-Gorbea 2011, 101.

53 Barrio Aldea - Maquedano Carrasco 1996, 271; Porres Martín-Cleto 1992, 38.

54 Rubio Rivera - TSIOLIS Karantasi 2004.

55 IBID. 229. 
En otro orden de cosas, la topografía del interior de la urbe debió favorecer la ubicación extramuros de los grandes monumentos lúdicos suburbanos. Pedro Alcocer ya identifica el exterior suburbano en la actual puerta de Bisagra y la calzada donde se localiza el circo y una de las necrópolis romanas, “... es gran prueba de lo dicho el nombre propio que hoy tiene una de las principales puertas de la ciudad a la que ellos pusieron el nombre de Vía Sacra, que ahora llamamos Bisagra." Aunque luego matiza que el origen del topónimo podría ser árabe, derivado de puerta de La Sagra. ${ }^{56}$ Parece evidente que el topónimo original es el de Via Sacra, independientemente de las transformaciones derivadas en época andalusí del mismo, lo que podría sugerir su asociación con la calzada de acceso principal a la ciudad con dirección a Augusta Emerita, o la prolongación de uno de los kardines principales, como ocurría con la homónima calle de Roma, que discurriría por la actual Avenida de la Reconquista. En su entorno se localizarían diversos edificios públicos y villae suburbanas como la de la Fábrica de Armas, actual Universidad de Castilla La Mancha. ${ }^{57}$ La necrópolis asociada a esta vía, la más antigua de las descubiertas hasta la fecha (segunda mitad del s. II d.C.) fue documentada por Palol a finales de la década de los 60 del siglo pasado. Este autor describe un tipo de tumba con ataúd de plomo, delimitada por tegulae colocadas de pie y, como cubierta, una fila de bipedalia en forma de tejado de doble vertiente. Todo el conjunto sellado por una masa de opus caementicium..$^{58} \mathrm{Se}$ conoce también una segunda necrópolis en el entorno de Santa Leocadia de Afuera, junto al puente de San Martín, ${ }^{59}$ fechada por su descubridor entre el s. III d.C. y los Ss. IV a VI (Fig. 15-33). ${ }^{60}$

A principios del s. XVII, Francisco de Pisa identifica tres edificios suburbanos, de origen romano, que aún permanecían en pie en esa época y que él interpreta como un circo, un templo adosado a su lado norte y un anfiteatro. Los dos primeros se orientarían hacia la denominada Via Sacra y el tercero hacia otra importante vía, de la que hoy en día no existe constancia, aunque por su proyección podría relacionarse con el hipotético kardo de la cloaca de San Agustín (Fig. 15-12). El circo lo describe como una "argamasa de piedra menuda y cal, que se ve en la vega fuera de los muros". El autor también describe un edificio adosado "que se conoce claro haber sido templo muy grande, que debió de ser de Marte, Venus o Esculapio porque estos tales fabricaba fuera de los muros". Por último, Pisa sitúa junto al Hospital Tavera el anfiteatro, del que dice "en la parte que llaman Covachuelas, hubo otro grande edificio que sin duda entiendo que fue teatro y también pudo ser anfiteatro". ${ }^{61}$

De este primer edificio, hasta la década de los 80 del pasado siglo, únicamente contábamos con el detallado estudio que hizo Rey Pastor. ${ }^{62}$ Sánchez Palencia y Sáinz

56 ALCOCER 1554, Libro I, fol. XIX.

57 Martínez - BlázQuez 1982; Rubio Rivera et alii 2010.

58 PALOL 1972, 133.

59 García Sánchez De Pedro 1996.

60 Otra necrópolis peor conocida es mencionada por Juan Moraleda y Esteban en una carta conservada en la Real Academia de la Historia. Se hallaría en el actual Paseo de la Rosa, en el entorno de la estación de tren en un paraje conocido como Huertas del Rey.

61 PISA 1605, Libro I, Cap. VIII.

62 Rey PASTOR 1932. 
Pascual proponen una periodización que aún se encuentra en vigor con una fase de fundación en torno a finales del segundo tercio del s. I d.C. y comienzos de Vespasiano. El circo posee unas dimensiones en torno a 423,10 x 100,80 m, con un área aproximada de $9.800 \mathrm{~m}^{2}$, y permaneció en uso hasta el s. IV o comienzos del V, ${ }^{63}$ aunque resulta complicado determinar si el espacio se utilizó con fines lúdicos hasta ese momento.

Respecto al anfiteatro, conservado bajo las viviendas del barrio de las Covachuelas, merece la pena detenerse en la evolución del parcelario y de la nomenclatura del callejero conforme avanza el s. XIX y comprender el porqué ha pasado casi desapercibido para la sociedad toledana (Fig. 3). En el plano de Maximiano Hijón de 1858 se identifica en planta el anfiteatro romano. Este se ve alterado tanto por la calle denominada entonces como Honda como por la carretera del camino de Madrid, bajo la que aún se conservaría parte del cierre noroeste del recinto. El plano de José Ibáñez Ibero de 1879 mantiene la misma distribución, aunque incorpora el topónimo de Anfiteatro como nombre de la calle, denominación que se pierde en el plano siguiente de 1882 de José Reinoso que vuelve a recuperar la antigua denominación de calle Honda, que se mantiene hasta hoy. ${ }^{64}$

Figura 3. Evolución de la planimetría del entorno del barrio de las Covachuelas (Archivo Municipal de Toledo).

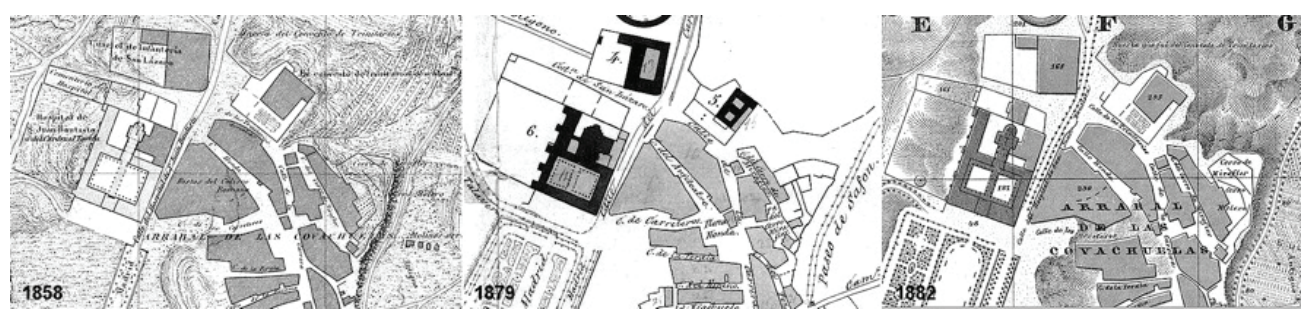

En la actualidad aún se conservan fosilizadas en las arquitecturas las trazas de este singular edificio. La fotointerpretación del mismo aplicada a las imágenes actuales del Instituto Geográfico Nacional, pertenecientes a los vuelos del PNOA de 2014 y las de 1973-1986 de los Vuelos Interministeriales, ha permitido atribuirle unas dimensiones en torno a $100 \times 115 \mathrm{~m}$ de diámetro en su contorno exterior, con un área aproximada de $9.800 \mathrm{~m}^{2}$ (Fig. 4). Esta interpretación difiere de la realizada en su momento por Alfonso Rey Pastor, ${ }^{65}$ ya que otorga al monumento un tamaño sensiblemente menor. En este sentido, proponemos la única hipótesis de ubicación y restitución hecha desde los años 30 del s. XX. Ejemplos de fosilización de las trazas de este tipo de monumentos los tenemos en la plaza del anfiteatro de Lucca (Italia), el teatro Marcelo o el circo de la Plaza Navona (Roma).

63 Sánchez Palencia - SÁinz Pascual 1988 y 2002; Rosado Tejerizo 2011.

64 Porres Martín-Cleto 2002, 140.

65 IBID. 141. 
Las dimensiones propuestas sitúan el anfiteatro de Toletum en un rango medio de los documentados en el Imperio. Anfiteatros similares los encontramos en Pollentia $(120 \times 96 \mathrm{~m})$, Lucca $(109 \times 70 \mathrm{~m})$, no siendo muy diferente en tamaño del emeritense $(124 \times 104 \mathrm{~m})$, e incluso aparentemente mayor que el tarraconense $(109 \times 70 \mathrm{~m}){ }^{66}$

Figura 4. Restitución de la planta del anfiteatro (Aérea de 1956 y 2014 del I.G.N.).
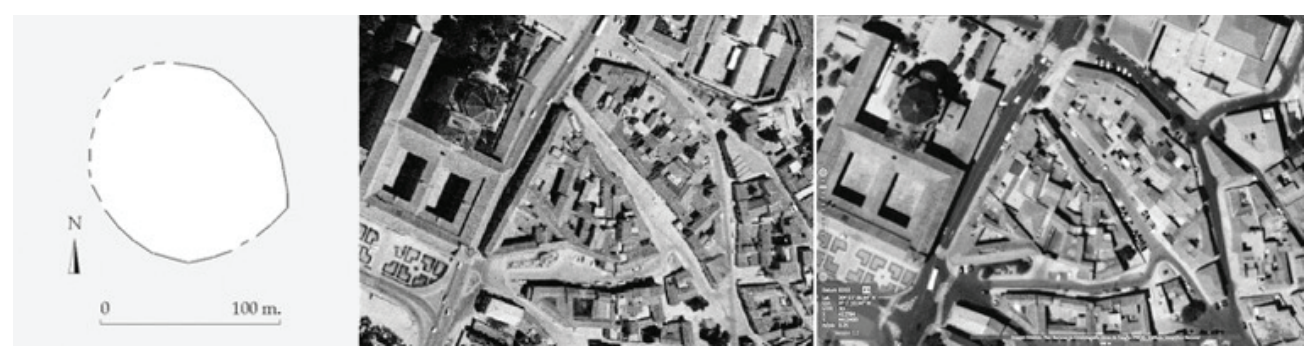

Por último, nada se conserva visible de las ruinas adosadas a la fachada noroeste del circo, que mencionan las fuentes, existiendo constancia de su traza cuadrangular en la planimetría histórica ${ }^{67}$ (Fig. 15-25). Recientemente se las ha llegado a interpretar como los restos de un teatro, hipótesis apoyada por Blázquez y en la línea de otras que las relacionan con otros usos. ${ }^{68}$ Otros autores como Rubio Rivera consideran que estos restos se justifican mejor como parte de una construcción pública de grandes dimensiones asociada a éste y adaptado a su trazado. ${ }^{69}$

Sea como fuere, la localización del teatro de Toletum aún sigue siendo una asignatura pendiente para los investigadores. Más allá de estas disquisiciones, es evidente que se debe considerar la búsqueda del teatro en otras zonas aunque en la historiografía tradicional y contemporánea no se recoja la existencia de ningún resto. En esta búsqueda habría que tener en cuenta bien las laderas que delimitan la muralla norte de la ciudad, o bajo los edificios que actualmente se localizan en torno a los principales caminos de acceso, además de los entornos del anfiteatro y del circo. Conviene recordar que los accesos a Toledo han sufrido numerosas transformaciones a lo largo de la historia, desde el aterrazamiento artificial del actual Paseo de Recaredo, al pie de la muralla norte, entre la puerta del Cambrón y la de Bisagra Antigua, hasta el allanamiento de la vaguada que existía entre el Hospital Tavera y la puerta Nueva de Bisagra. Esta zona fue usada como muladar hasta 1538, fecha en la que el corregidor de Toledo, Don Pedro de Navarra, elimina la depresión que existía entre ambos monumentos y crea una amplia llanura que hoy se corresponde con el Paseo de Merchán. ${ }^{70}$ Como ocurre con Augusta Emerita o Segobriga, la localización del teatro toledano parece más lógica en el entorno del anfiteatro, bien bajo el Hospital Tavera

\footnotetext{
66 Martín Escorza 2008, 192.

67 Ver Francisco Coello 1858 o Alfonso Rey Pastor 1926.

68 Blázquez 2012, 84; Carrobles Santos 2001; Pisa 1605.

69 Rubio Rivera 2010, 49.

70 RAMÓN PARro 1837, 361.
} 
al este, o en algún punto de la depresión natural hacia el río (en el actual barrio de las Covachuelas), lo que le hubiera permitido excavar en la ladera parte de su graderío. En esta ubicación, además, teatro y anfiteatro serían contemplados no sólo desde la ciudad, frente a ellos, sino desde el Paseo de la Rosa al este, camino a Corduba, y Via Sacra al noroeste, camino a Augusta Emerita ${ }^{71}$ (Fig. 15). Sin embargo, aún sería plausible una tercera hipótesis para la localización de este teatro: su construcción intramuros, que aprovecharía alguna de las colinas, laderas o desniveles al oeste de la ciudad. El fuerte carácter propagandístico, a la par que multifuncional de los edificios teatrales pudo motivar una construcción previa a la del resto de edificios públicos, como sucede en numerosas ciudades de provincias y recientemente se ha propuesto también para la primitiva Complutum..$^{72}$

Además de la Via Sacra, otra importante vía de acceso, en este caso con dirección este-oeste, la encontramos sobre el actual paseo de la Rosa, el mencionado camino a Corduba, donde también se han encontrado numerosos restos romanos. Entre ellos destacan las tumbas previamente mencionadas, y descritas por Juan Moraleda y Esteban, además de una natatio en Cabrahigos, perteneciente a un supuesto complejo termal de carácter suburbano que su excavador fecha en la segunda mitad del s. I d.C., a comienzos de la dinastía Flavia, aunque no deja claro si podrían asociarse o no con una gran villa. ${ }^{73}$ Esta vía debía de continuar por todo el frente amurallado hasta encontrase con el actual puente de Alcántara (Fig. 15-34).

Para terminar de definir el ámbito suburbano y la organización de la urbe debemos destacar las principales características de otras construcciones auxiliares como son el acueducto y los puentes. En cuanto al acueducto, ha sido ampliamente tratado en la bibliografía ${ }^{74}$ y constituye uno de los restos de ingeniería romana más representativos de la ciudad. La obra debía ser imponente y salvaba los $215 \mathrm{~m}$ del cortado del río. Aunque hoy sólo se conserva el arranque de uno de sus arcos, los cimientos de sus pilares y buena parte de las canalizaciones que traían el agua a Toletum. Este acueducto se abastece de un sistema de presas localizadas $40 \mathrm{~km}$ al este de la ciudad, junto a una compleja red de canales que da servicio a edificaciones de todo tipo, entre las que destacan varios complejos termales del interior de la ciudad y que trataremos más adelante. Por su parte, se conservan en la actualidad dos puentes medievales que cruzan el río, el de San Martín y el de Alcántara, este último de posible origen romano, conservando en sus cimientos, o reutilizados, elementos constructivos de dicha época. ${ }^{75}$

71 Palomero Plaza 2001.

72 AzcÁRraga CÁmara - Ruiz TABOAda 2012-2013.

73 Rojas Rodríguez Malo 1996, 79-80.

74 Aranda Alonso et alii 1997; Arenillas Parra et alii 2009; Barahona Oviedo et alii 2014.

75 RomÁn MARTínez 1942. 


\section{Las cloacas de la Bajada del Barco}

Hasta el momento hemos visto como una gran parte de la información empleada para definir tanto el primitivo asentamiento carpetano como la distribución suburbana de Toletum proviene en su mayoría de las fuentes históricas, complementadas con los escasos restos materiales publicados. Más complicado, si cabe, resulta establecer la evolución interna de la ciudad antigua. La gran cantidad de restos arqueológicos descubiertos carecen en la mayoría de los casos de un contexto arqueológico asociado a ellos, lo que complica cualquier intento de sistematización. Esto es debido tanto a los procesos de deposición normales en este tipo de ciudades, que hace que las sucesivas reutilizaciones del mismo espacio hagan desaparecer su estructura primaria, como a la ausencia de excavaciones sistemáticas publicadas.

En el ocaso de las diferentes épocas, los núcleos urbanos sufren reformas interiores para adaptarlas a las costumbres y tradiciones de sus sucesores. En el caso de Toledo, el reino visigodo probablemente conservó la esencia de la ciudad antigua, prueba de ello es la escasez de restos de este periodo en el interior del casco histórico, puesto que debieron reutilizar una gran parte de la ciudad heredada. El caso contrario lo tenemos tras la dominación musulmana, con un cambio drástico en el modelo de ciudad en la que la saturación del parcelario y la creación de una nueva urbanística van a caracterizar su desarrollo. ${ }^{76}$ A pesar de los cambios sufridos en el Toledo andalusí, también se reutilizaron infraestructuras preexistentes en sus nuevos modelos urbanísticos. Por desgracia, son pocas las fuentes textuales que hablen del uso de elementos antiguos en las nuevas medinas. Ejemplo documental de estas reutilizaciones lo tenemos en un escrito almohade que habla de la recuperación de un antiguo saneamiento romano para traer agua a la ciudad de Sevilla, fechado en el s. XII y escrito por Ibn Sahib al-Sala. ${ }^{77}$

En el análisis de estas transformaciones, es lógico pensar que la red de evacuación de aguas pública es la que mejor ha soportado el paso del tiempo. Su conservación se relaciona con los beneficios que su mantenimiento aporta a la comunidad y se debe a su localización, en las vaguadas y principales vías de evacuación pluviales de la ciudad. ${ }^{78}$ Por tanto, a la hora de analizar el diseño urbano de cualquier ciudad antigua, el estudio de las redes de canalización es clave para entender la distribución superficial de la misma, ordenada en torno a calles principales bajo las que suelen discurrir estas cloacas.

En Toletum se conoce el momento de construcción de estas canalizaciones y su uso a lo largo del Impero, no obstante, se ha prestado poca atención tanto al proceso de integración y conservación de estas mismas redes en épocas posteriores tardorromanas o visigodas y, más recientes, bajo medievales. De hecho, muchas de ellas han permanecido en uso hasta hace pocos años. En las dos cloacas documentadas

76 Ruiz TABOADA 2012.

77 Huici Miranda 1969, 69, 190-191.

78 FARIÑA TOJO 1996. 
en el número 2 de la Bajada del Barco ${ }^{79}$ se puede reconstruir dicha evolución, no sólo porque contamos con el trazado romano original del sistema de evacuación de ambas, y su posterior reconstrucción y reutilización medieval de la primera de ellas, sino porque hemos podido documentar la fase de abandono de la segunda, fechada únicamente en época romana y que va a desaguar posiblemente en la primera. Con respecto a su diseño, llama la atención la dirección del flujo de ambas. Mientras que la primera y principal sigue la escorrentía natural de la Bajada del Barco, la segunda sigue dirección norte, aunque con intención de confluir en la principal (Fig. 5).

Figura 5. Solar de la Bajada del Barco. Planta de la excavación y secciones de la cloaca medieval.

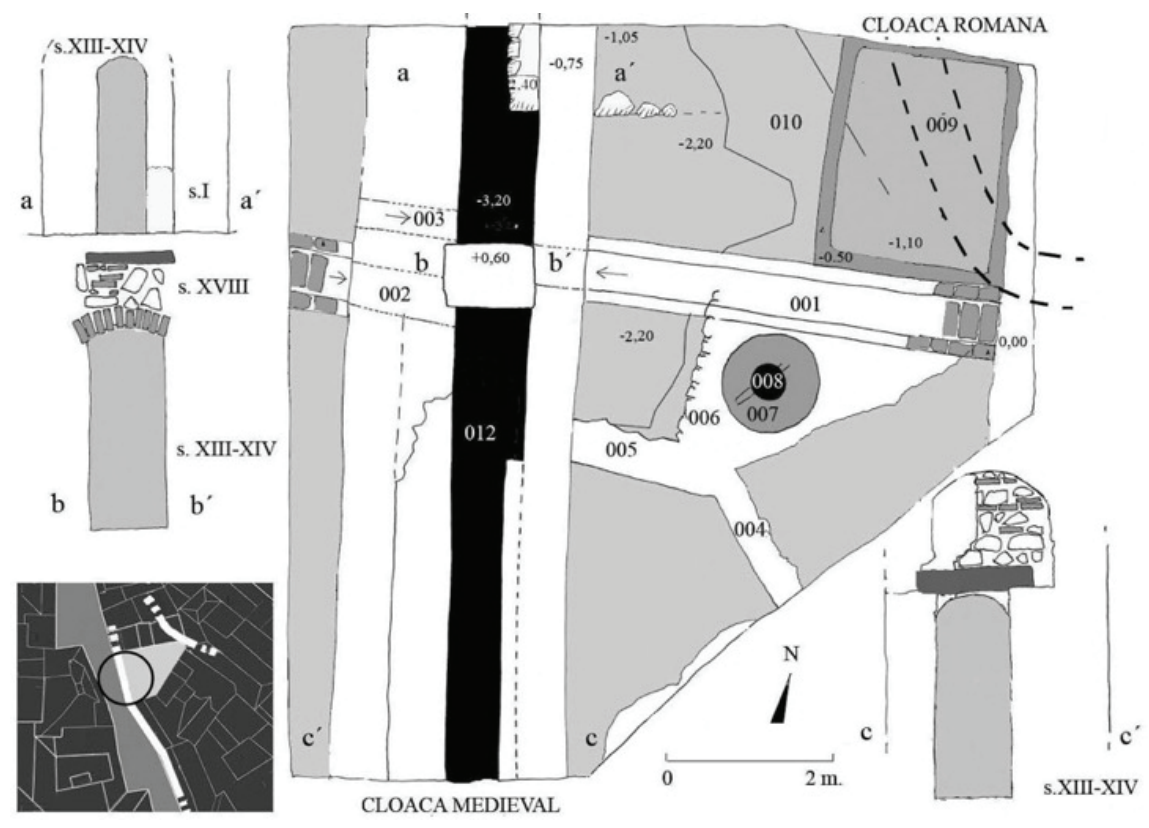

La primera cloaca documentada (Fig. 5), recorre longitudinalmente el actual número dos de la Bajada del Barco y continúa hacia el sur hasta llegar al río. Posee mayor entidad y se encuentra perfectamente alineada con la calle original es decir, con la línea de arroyada de la ladera del cerro donde se encuentra. Aunque esta cloaca se encuentra reformada en época medieval, su traza es romana. Esta canalización se caracteriza por tener unas dimensiones similares a las romanas, aunque en este caso, los muros son de mampostería y la cubierta se hace mediante una bóveda de ladrillo trabada con cal. El trazado no es recto en toda su longitud excavada sino que

79 Excavación dirigida por Beatriz Martín Eguiguren y Arturo Ruiz Taboada a finales de 2011 con autorización de la Viceconsejería de Cultura de la Junta de Comunidades de Castilla La Mancha. 
se adapta con diferentes quiebros a las sinuosidades de la calle y posee cuatro fases constructivas, de las que aquí nos interesa principalmente la romana: ${ }^{80}$

Fase I. Se corresponde con el trazado original de época romana. Desde un punto de vista constructivo, la roca se encuentra cajeada generando el fondo de la cloaca. Algunos tramos conservan restos de opus caementicium como cimiento del canal medieval, así como un esquinal de sillares in situ, integrado en el recrecido medieval de la cloaca.

Fase II. Bajo Medieval. A esta fase pertenece la mayor parte de la fábrica conservada. Su fundación se encuentra en relación con la reestructuración de la trama urbana que se produce a finales del XIII (Fig. 6-1). La cubierta es abovedada sobre muros de mampostería.

Fase III. Moderna. Se ha documentado una importante reforma de la misma con estructuras abovedadas y registros laterales, fechada en el s. XVIII.

Fase IV. Contemporánea. Es la que más la ha deteriorado. Consiste en diversos parches y reformas fruto de la introducción de nuevos registros, en esta ocasión rompiendo las estructuras más antiguas y reformando su fábrica para evitar el colapso de las estructuras. Fechada a lo largo del XX.

Figura 6. Cloacas principal (1) y secundaria (2) de la Bajada del Barco.

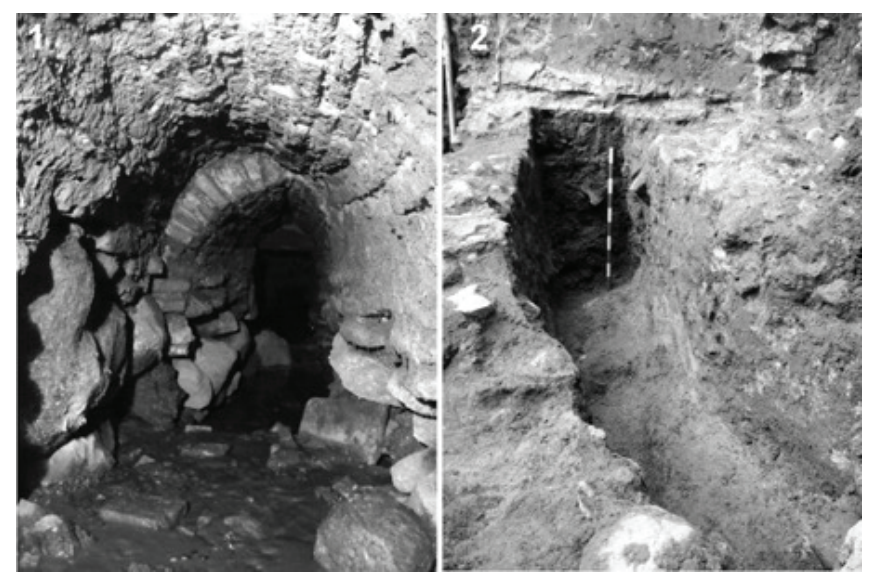

La segunda cloaca, enteramente romana, posee carácter secundario y su orientación es completamente diferente, hacia el norte, yendo posiblemente a desembocar en la principal (Fig. 6-2). Está fabricada en opus caementicium, tallada en la roca madre y con la bóveda caída fruto de su pérdida de uso y la construcción posterior de una pileta perteneciente a la ocupación medieval del espacio. Llama la atención su trayectoria, a contra ladera que respondería posiblemente a necesidades de espacio en el momento de su creación. El hecho de que, además, su recorrido no sea lineal podría deberse a la necesidad de salvar posibles obstáculos constructivos no previstos en origen. Esta circunstancia, junto a sus dimensiones, algo más reducidas que

80 Ruiz TABOAda 2012, 95. 
el resto de cloacas de las mismas características en Toletum, hace pensar en que nos encontramos ante una cloaca que no forma parte del sistema público hidráulico, sino a una edificación de carácter privado (Fig. 7).

Figura 7. Dibujo y matriz estratigráfica de la excavación de la cloaca de la Bajada del Barco.

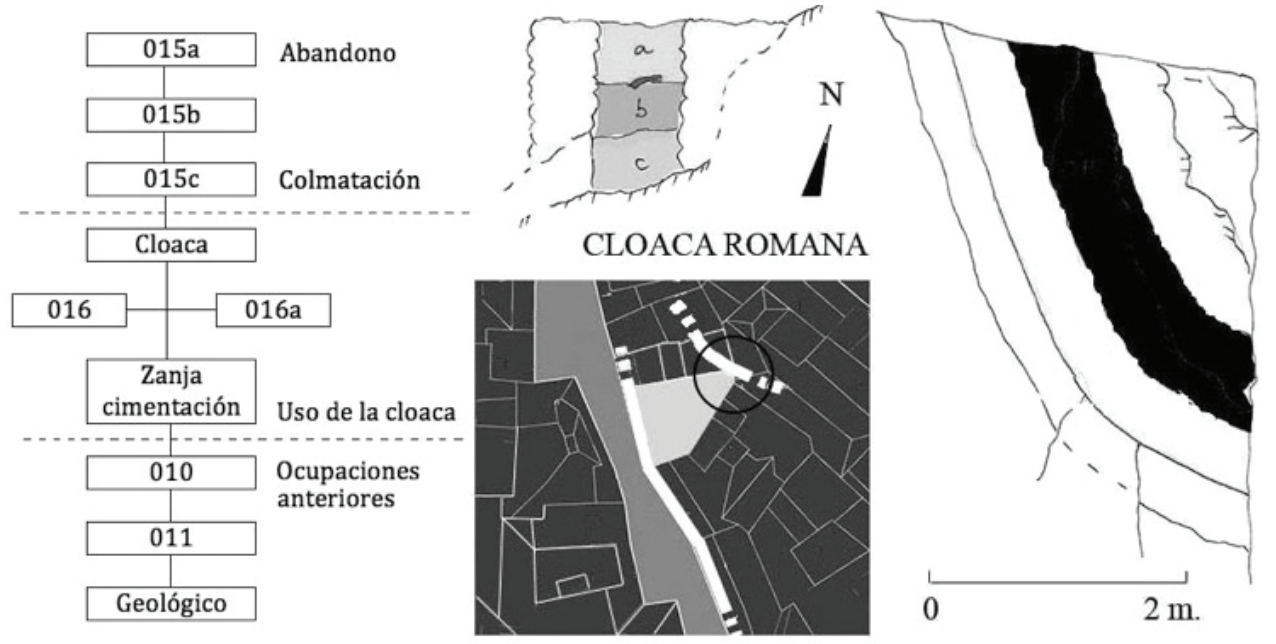

Los materiales documentados en su excavación aportan la cronología tanto de su fundación como de su abandono. De un lado, destacan sendas monedas (Fig. 8), una descontextualizada de época republicana y otra de época tardorromana, en uno de los estratos de abandono de la cloaca. La primera apareció en los niveles de revuelto medieval y se trata de un As de la ceca de Kese, muy desgastado en ambas caras y con un resello punteado con las letras $\mathrm{S}$. C. en el anverso ( $26 \mathrm{~mm}$ de diámetro y $8,1 \mathrm{gr}$.). Llama la atención la presencia de este tipo en Toletum ya que se relaciona con monedas de la zona minera de Sierra Morena, de entre finales del s. II y la época de Augusto, donde esta contramarca se interpreta como Societas Castulonensis, indicando la relación comercial entre Castulo y Kese.$^{81}$ La dispersión de estas monedas y otros objetos con esta contramarca indica que esta compañía minera tenía sus intereses repartidos por gran parte de Hispania. Hasta la fecha sólo conocíamos ejemplos en la Ulterior, ${ }^{82}$ por lo que el presente hallazgo amplía su presencia también en la Citerior.

Por su parte, la segunda moneda, como hemos mencionado, ha servido para concretar el momento de abandono de la cloaca romana, ya que se documentó en el último estrato de colmatación de ésta (UE 15a) que enseguida describiremos en conjunto. Pertenece al emperador Diocleciano (284-305 d.C.) y puede fecharse a finales del s. III o inicios del s. IV d.C. Con un peso de 2,7 gr y $21 \mathrm{~mm}$ de diámetro se correspondería con una fracción radiada quizá posterior a la reforma realizada por este emperador, que produjo su desaparición entre el 293 y 294 a.C., aunque algunas

81 Díaz Ariño 2008, 82, 294; Domergue 1971, 351-353; JimÉnez Ávila 1989-1990, 126.

82 IBID. 294. 
cecas continuaron utilizando la corona radiada con posterioridad. Una de esas cecas fue Alejandría, a la cual pertenece la presente moneda, acuñada en concreto en la segunda oficina. La leyenda del anverso sería la siguiente: IMP C DIOC(L)ETI(AN) VS PF AUG con el busto de corona radiada mirando a la derecha. En el reverso la leyenda es: (C) ONC (ORDIA MIL) ITVM, con una letra B en la parte inferior del campo que indica la segunda oficina y ALE en el exergo, haciendo alusión a Alejandría. En cuanto a las figuras representadas, aparece el emperador a la izquierda, de pie, recibiendo la victoria sobre un globo de manos de Júpiter, también de pie y a la derecha sosteniendo un cetro.

Figura 8. Monedas aparecidas en el transcurso de la excavación de la Bajada del Barco.
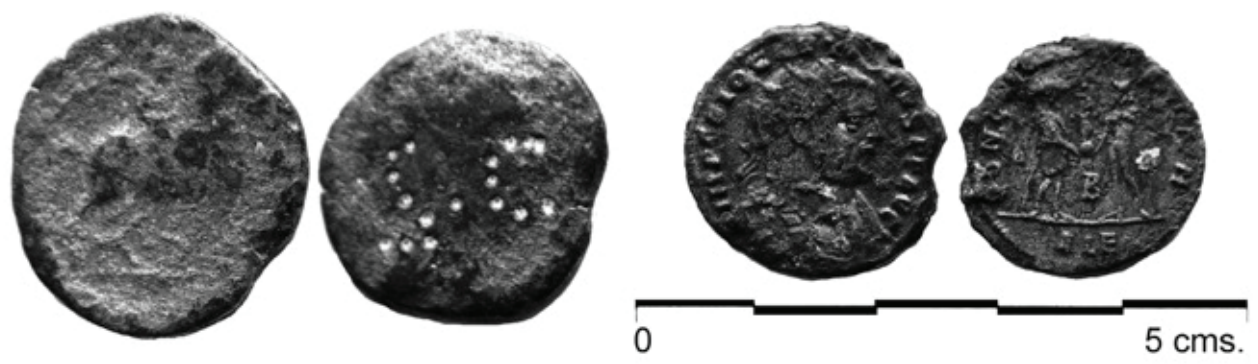

El resto del material documentado se ha estructurado su estudio en su contexto estratigráfico (Fig. 7), comenzando la descripción por los estratos más antiguos. En dichos estratos destaca la presencia de elementos de gran calidad que aportan, además, una cronología altoimperial. La UE 010 constituía un nivel de desecho, homogéneo y bastante amplio que se extendía por gran parte del solar excavado y era cortado por la zanja de cimentación de la cloaca. El material en esta unidad estratigráfica es abundante, con un total de 40 fragmentos, además de dos piezas destacadas: una estatuilla de cerámica fracturada por la mitad y una pieza cerámica circular a modo de botón, con líneas incisas formando una retícula geométrica (Fig. 9). En el primer caso la pieza podría corresponderse con una figurita de culto de un larario, quizá la representación de la diosa Venus, una de las divinidades más frecuentes en la iconografía coroplástica hispana. ${ }^{83}$

En cuanto al material cerámico selecto se documentan algunos fragmentos claramente atribuibles a mediados o tercer cuarto del s. I d.C. Destaca el hallazgo de un borde perteneciente a un plato de engobe rojo pompeyano de la forma 33 del DICOCER (Fig. 10-1), además de varios fragmentos de TSH que se adscriben a los primeros momentos de la producción, entre ellos una Drag. 37a (Fig. 10-2), dos Drag. 27 (Fig. 10-3,4), la primera con parte del sello del alfar riojano de $\mathrm{MCR}^{84}$ (aunque con la última letra descabezada), una Conspectus 1 de gran calidad (Fig. 10-5) y la base de una Drag. 17 o 15/17 (Fig. 10-6) con un extremo del sello conservado (sin letras) y parte de un grafito en la zona inferior del fondo. Merece la pena detenernos en el

83 Ramos 2008, 780.

84 Identificación que agradecemos a Luis Carlos Juan Tovar. 
alfarero que responde al sello MCR, identificado por Blanco García y Juan Tovar ${ }^{85}$ con $M$ (arcus) C(ornelius) R(eburrus) cuyas producciones son consideradas precoces entre la sigillata hispánica, con una cronología de entre Claudio y Nerón. ${ }^{86}$ En nuestro caso nos acercamos más a Nerón debido a la evolución del pie, que ya carece de la característica molduración en forma de acanaladura que era común en las producciones sudgálicas.$^{87}$ Este hallazgo en Toletum supone, además, la documentación más meridional de una pieza de este alfarero, que hasta el momento no se hallaba al sur de Coca. ${ }^{88}$ Se constatan una vez más, como sucede con los ejemplares hallados en Tarazona o Arcobriga, las estrechas relaciones comerciales cerámicas entre el valle del Ebro y la Meseta a través del Jalón. ${ }^{89}$

Figura 9. Fragmento de estatuilla cerámica y botón cerámico (UE 010).
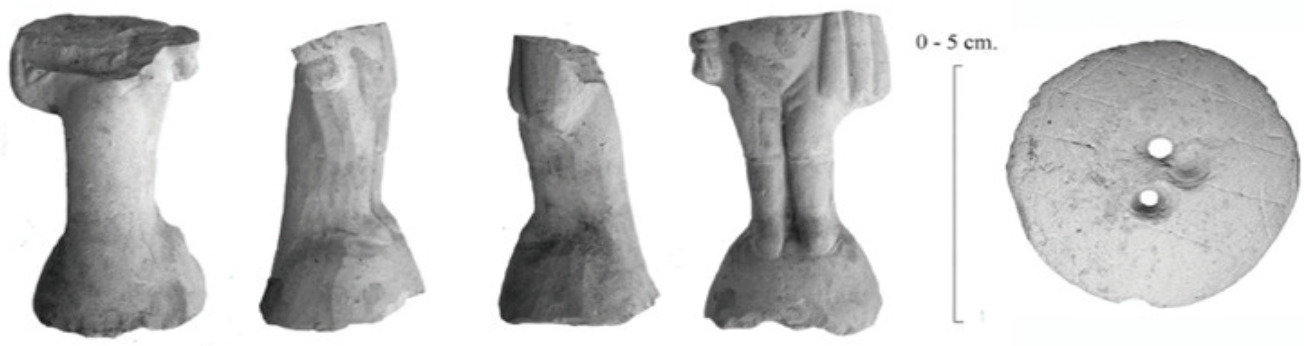

Por otro lado, también llama la atención la presencia de varios grafitos (en fase de estudio) sobre TSH o TSHB en este contexto. En el conjunto de la TSH de este estrato se documentan tanto formas lisas como decoradas, con un predominio de los alfares riojanos destacando la presencia de diversos punzones característicos como los motivos circulares (lisos, ondulados, sogueados, concéntricos) o vegetales (rosetas) y "V" inscrita en motivo circular doble. Otros elementos característicos altoimperiales son las producciones pintadas de tradición indígena, un total de 11 fragmentos entre los que destacan varios galbos con decoración bícroma o polícroma y 2 bordes pertenecientes a la forma 18B de Abascal (Fig. 10-7,8). Se documentan también otras producciones de TSH altoimperiales, pero por su menor calidad son algo posteriores, de finales del s. I d.C., como puede ser el borde de Ritt. 8 (Fig. 10-9), Drag. 44 (Fig. 10-10), Drag. 27 de mayores dimensiones que las anteriores (Fig. 10-11) una Drag. 29/37 (Fig. 10-12) y otra Drag. 29 (Fig. 10-13). Por último, cabe destacar en este estrato una jarra de cerámica común reductora con asa, de la forma Vegas 39a, con una cronología que puede oscilar entre la segunda mitad del s. I a.C. y el s. I d.C. ${ }^{90}$

85 Blanco García - Juan Tovar 1996, 148.

86 SÁenz Preciado 2000, 288; Romero Carnicero 1985, 61 ss.

87 Romero CARNICERO 1984, 95; ID. 1984a, 349.

88 Blanco garcía - Juan Tovar 1996, 148; SÁenz Preciado 2000, 291.

89 SÁenz Preciado 2000, 288.

90 Vegas 1973, 93-95. 
Figura 10. Cerámicas pertenecientes a los estratos más antiguos $(010$ y 011).

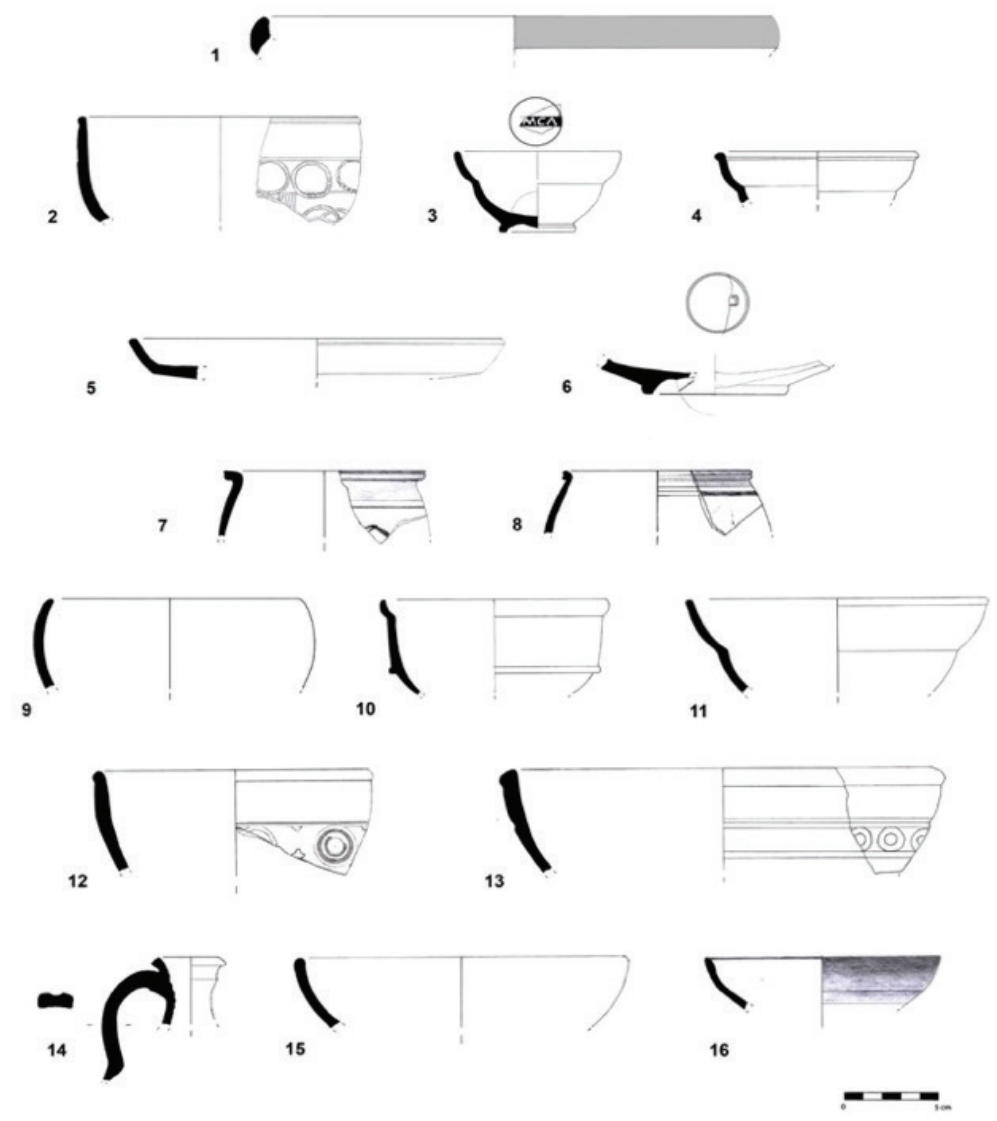

La unidad estratigráfica sobre la que se apoya la que acabamos de describir es de escasa potencia y está ya en contacto con el geológico, conteniendo fragmentos de la roca meteorizada (UE 011). Aunque el material aquí es mucho más escaso (tan sólo 13 fragmentos cerámicos y un pequeño tapón o remache de bronce) merece la pena destacar dos fragmentos que apuntan hacia el mismo ámbito cronológico altoimperial ya descrito en la UE 010, evidenciando que la ocupación del entorno no se produce con anterioridad al s. I d.C. Se trata de un fragmento de TSHB de la forma 9 (Fig. 1015) y otro pequeño vaso de tradición indígena de la forma 16 de Abascal (Fig. 10-16). Cabe destacar también dos pequeños galbos decorados de TSH de primera época, una base algo posterior, además de dos fichas de cerámica común, una de ellas fracturada.

En resumen, los estratos sobre los que se construye la cloaca aportan los materiales más antiguos documentados en esta intervención, en consonancia con el resto de los que se asocian a estructuras constructivas como los de la muralla y el circo, anteriormente mencionados, que hablarían de una ciudad plenamente urbanizada a finales de 
época Julio-Claudia, en torno al tercer cuarto del s. I d.C. Por otro lado, el hecho de que los materiales romanos documentados en este entorno urbano se hallen directamente sobre el geológico podría ser un indicador más de que en época prerromana la población se concentrara en una zona más reducida. Por otro lado, la presencia de materiales de la segunda mitad del s. I d.C. en el estrato cortado por la zanja de cimentación de la cloaca indica que este tramo debió construirse con posterioridad a la red de saneamiento principal, posiblemente en los momentos finales del s. I d.C.

Figura 11. Fragmentos cerámicos del relleno de la zanja de cimentación de la cloaca (016 y 016a).
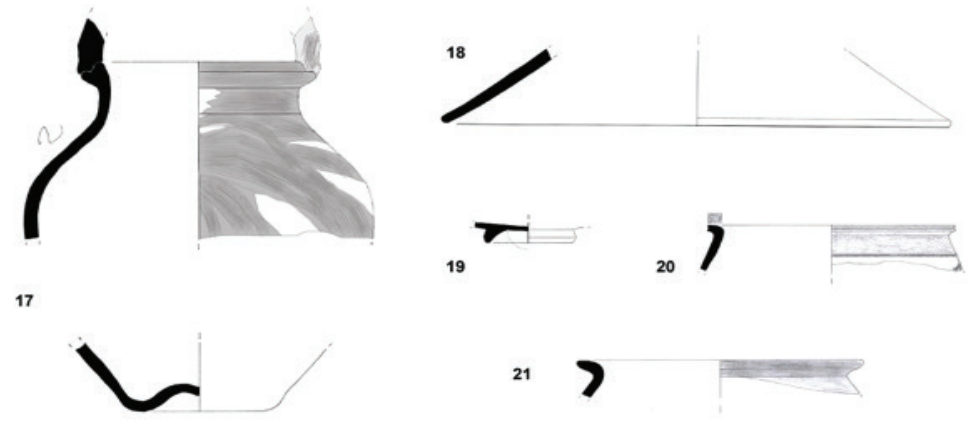

21
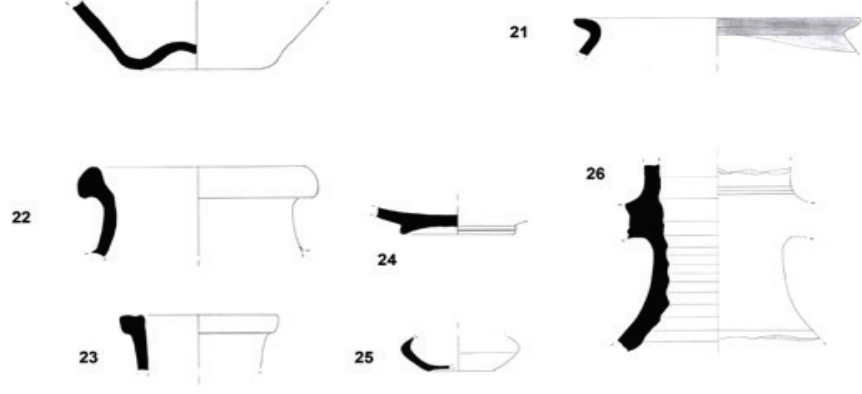

Por su parte, en los dos rellenos de la zanja de cimentación de la cloaca (uno de ellos homogéneo y el otro una bolsada cenicienta, 016 y 016 a respectivamente) se recogieron un total de 40 fragmentos cerámicos y uno de vidrio azulado altoimperial. Este último elemento apareció bastante completo a pesar de su fragilidad, identificándose el cuello de una botella Isings 50a con el arranque del asa, forma que se fecha entre el segundo tercio del s. I y finales del II d.C..$^{91}$ Entre el material selecto destacan tanto cerámica de almacén y transporte como vajilla o elementos de iluminación (Fig. 11). La primera forma que llama la atención es una tinajilla con borde biglobular y asa de cesta, de la que se puede reproducir el perfil completo, con base umbilical, decoración pintada en rojo anaranjado aplicada a brochazos y un grafito con la letra "N" al inicio del cuerpo (Fig. 11-17). Tanto por su tipología y decoración como por su

91 ISINGS 1957. 
contexto se correspondería con una producción romana altoimperial poco común, ${ }^{92}$ con ejemplares similares en Cauca aunque lisos y de cronología tardía. ${ }^{93}$

La TSH y el resto de cerámica documentada en estos estratos se corresponde, de nuevo, con producciones altoimperiales, lo que no es de extrañar ya que es muy posible que utilizaran el sedimento que extrajeron al excavar la zanja para su relleno. Entre la TSH predominan las formas lisas y de gran calidad, adscribibles a la segunda mitad del s. I d.C., destacando un fragmento de tapadera de la forma 7 de Mezquiriz (Fig. 11-18) y una pequeña base (Fig. 11-19). En cuanto a las cerámicas pintadas de tradición indígena se repite, de nuevo, la forma 18 de Abascal en una ocasión con seguridad (Fig. 11-20) y quizá en otro fragmento de galbo con un engobe rojizoanaranjado muy brillante, dos líneas negras horizontales y parte de un grafito en forma espigada. Se documenta también una tinajilla común con pintura rojo-vinoso aplicada a brochazos, y por tanto desigualmente repartido (Fig. 11-21). Respecto al resto de las producciones cerámicas, destacan dos fragmentos de ánforas (la segunda del estrato 016a) posiblemente de origen mediterráneo oriental o Rodio, posiblemente Dressel 2/4 ${ }^{94}$ con una cronología genérica del s. I d.C. (Fig. 11-22,26), uno de jarra o cántaro similar al tipo 38 o 39 de Vegas (Fig. 11-23) y una base de cuenco oxidante (Fig. 11-24). Por último hay que mencionar el hallazgo de un fragmento de lucerna oxidante, que por desgracia no conserva ni el pico, ni el disco, ni el asa, lo que complica su clasificación, aunque por el contexto en el que se encuentra consideramos que respondería a una tipología altoimperial.

Resta por analizar el material documentado en los estratos de colmatación y abandono de la cloaca, donde comenzamos a ver cambios respecto al panorama anterior. En el primer estrato de relleno, que se deposita directamente sobre el fondo de la cloaca (UE 015c), se documentan un total de 44 fragmentos cerámicos, en su mayoría producciones comunes. En este contexto aparecen materiales de cronología altoimperial, aunque escasos y junto a otros que podrían ser más tardíos, como es habitual en los vertidos de desecho. Los materiales más antiguos se corresponden con 8 pequeños fragmentos indeterminados de TSH altoimperial y dos fragmentos de TSHB, uno de ellos un fondo muy deteriorado (quemado en parte) perteneciente a una forma cerrada indeterminada (Fig. 12-27). Entre la cerámica común cabe destacar un asa de cántaro o jarra (Fig. 12-29) de cronología imprecisa, similar a la forma 44 de Vegas y un posible borde de ánfora también indeterminada (Fig. 12-28). Respecto al segundo estrato de colmatación (UE 015b) contiene escaso material cerámico, un total de 25 fragmentos, todos de muy pequeño tamaño. Continúan documentándose algunos materiales altoimperiales aunque más bien del s. II d.C., como algunos pequeños fragmentos de TSH u otros pintados de tradición indígena. Destaca la presencia de un asa anular de lucerna (Fig. 12-30), con 4 líneas incisas en la parte superior, decoración que se utiliza tanto en el Alto como en el Bajo Imperio aunque, desafortunadamente, de tipología indeterminada.

\footnotetext{
92 Agradecemos a J. F. Blanco García la clasificación de esta pieza.

93 Blanco García et alii 2012-2013, 104.

94 Identificación que agradecemos a Rui Roberto de Almeida.
} 
Figura 12. Fragmentos cerámicos pertenecientes a los estratos de colmatación y abandono de la cloaca $(015 \mathrm{c}, 015 \mathrm{~b}$ y $015 \mathrm{a})$.

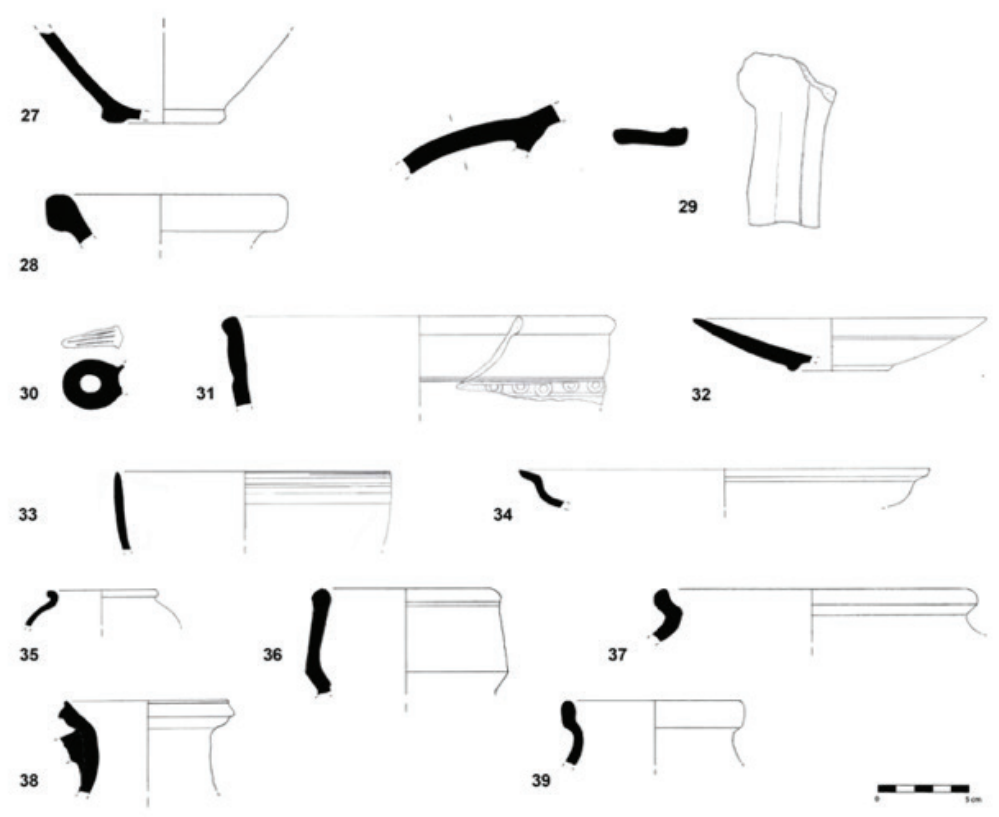

Por último, el estudio de los materiales del estrato más reciente de colmatación de la cloaca (015a) ha reflejado un panorama definitorio, que muestra la pérdida total de uso de la cloaca en época bajoimperial. Recordemos que la moneda documentada en este estrato aportaba una cronología de finales del s. III o principios del IV d.C., en este caso orientativa, ya que aparecen materiales cerámicos más tardíos y que fechan, por tanto, la pérdida de uso de la cloaca. En total se recogen 60 fragmentos cerámicos, en su mayoría no selectos y pertenecientes a producciones tardías. Comenzando por los materiales de desecho más antiguos, destacan algunos elementos altoimperiales de finales del s. II d.C. como un borde decorado de Drag. 37 (Fig. 12-31) de los alfares riojanos o algún pequeño fragmento de pared de cerámica pintada de tradición indígena. Se documenta también un fragmento de vasito ovoide, oxidante y con restos de engobe amarillento al exterior y negro al interior, posiblemente perteneciente a una producción engobada indeterminada (Fig. 12-35). En cuanto a las producciones comunes, se documenta una jarra claramente tardía, similar a la forma Vegas 42 (Fig. 12-36), con un barro de color ocre claro y paralelos, por ejemplo, en Pollentia entre la segunda mitad del s. III d.C. y el s. IV ${ }^{95}$ otras jarras de cronología más imprecisa similares al tipo 39 (Fig. 12-38) o 44 (Fig. 12-39) y una olla de borde vuelto y hendidura para tapadera (Fig. 12-37).

Respecto a los diversos fragmentos de TSHT, varios de ellos marcan la fecha final de colmatación de la cloaca. Destacan tres producciones tardías, todas ellas presentes

95 Vegas 1973, 101. 
y bien estudiadas en yacimientos como Quintanilla de la Cueza, Palencia. ${ }^{96}$ Se documenta un platito de la forma 77 de Mezquíriz o Palol 5 (Fig. 12-32), un cuenco de la forma 8 de Mezquíriz (Fig. 12-33) que imita en la delgadez de sus paredes a las producciones africanas del grupo $\mathrm{C}$ y un plato de la forma Palol 3 (Fig. 12-34). Tanto por la forma, como por el tipo de pasta y barniz probablemente se trata de producciones de la segunda mitad del s. IV d.C. ${ }^{97}$ por lo que ésta podría ser la fecha de pérdida de uso de al menos este tramo de la cloaca, precisando la cronología aportada por la moneda de Diocleciano.

\section{Consideraciones en torno a la distribución interna de la ciudad}

Las cloacas de la Bajada del Barco no sólo dan idea de la complejidad estratigráfica que existe en ciudades históricas como Toledo, sino que aportan la información necesaria para analizar los contextos urbanos a los que se encuentran asociadas. En este apartado contextualizaremos dichas cloacas en el trazado urbano conocido de Toletum, observando que, si bien resulta arriesgado hablar de una trama ortogonal generalizada en la ciudad, sí resulta posible empezar a identificar, al menos, un sector en el centro urbano.

Sin embargo, en algunos casos encontramos ramales de cloacas que no son exactamente rectilíneos o que no siguen la alineación de un hipotético trazado ortogonal, como la cloaca del Juego de Pelota ${ }^{98}$ o una de las dos de la Bajada del Barco, fuera de este sector central de la ciudad y que pueden responder bien a una fase constructiva diferente o bien a la existencia de esa heterogeneidad de la que hablaba Blázquez. ${ }^{99}$

Para desarrollar dicha hipótesis, se parte de la propuesta de identificación ideal de los dos ejes principales que articulaban la ciudad. Éstos, según los cánones establecidos, la recorrerían de noroeste a sureste y suroeste a noreste. Dichos ejes coincidirían en gran medida con el trazado viario prerromano propuesto por Fernández del Cerro y Barrio Aldea, basado en su topografía, con una orientación ligeramente distinta de la que en su día propuso Rubio Rivera. ${ }^{100}$ Independientemente de que puedan existir otros sectores urbanizados con diferente diseño, lo que resulta evidente es que el sector central y más elevado del cerro, poseía una disposición topográfica con una tendencia a la horizontalidad o fácilmente allanable en ciertas zonas, lo que pudo permitir el planteamiento de dicho diseño ortogonal (Fig. 13).

\footnotetext{
96 JuAn TOVAR 2000.

97 Catalogación que agradecemos a Luis Carlos Juan Tovar.

98 Ruiz TABOADA - MENCÍA 2005.

99 BLÁzQUEZ 2012.

100 Fernández del Cerro - Barrio Aldea 2002, 366; Rubio Rivera 1997.
} 
Figura 13. Corte topográfico del cerro en relación con dos de los posibles ejes principales de la ciudad romana mencionados en el texto.
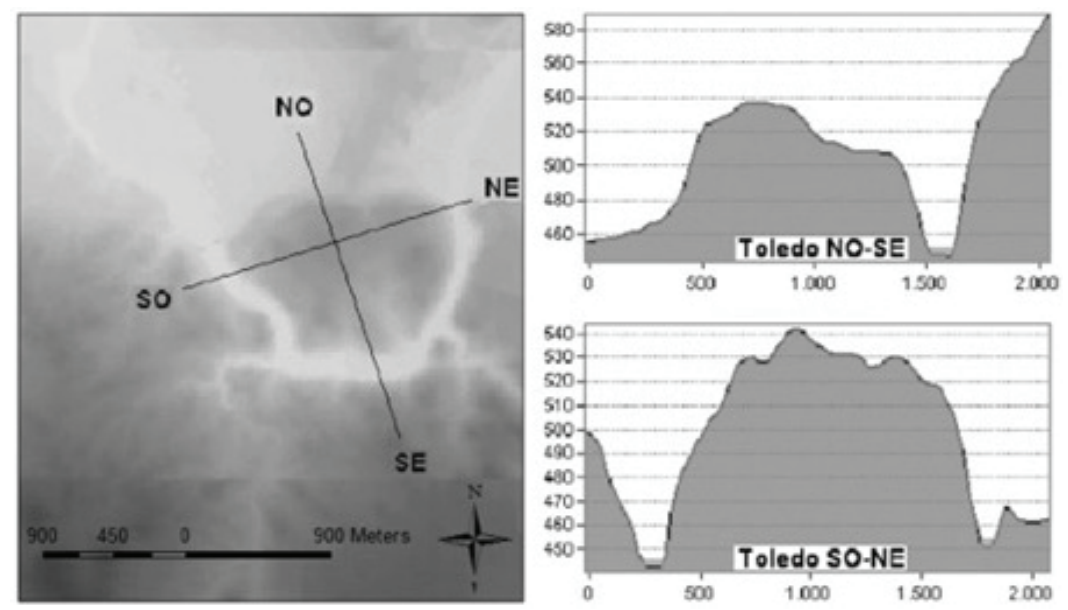

Para entender la posible existencia de dicha trama en este sector central, no extrapolable al resto de la ciudad por cuestiones orográficas, es necesario analizar la localización y orientación de alguno de los hallazgos descubiertos en las últimas décadas. Desde tramos de muro, restos de pavimento de calles y el sistema de canalización que discurría bajo ellas, a sistemas relacionados con el abastecimiento de agua y las diferentes vías de acceso a la ciudad como caminos y puentes, hoy desaparecidos.

El primer elemento que debemos destacar en la presente propuesta de trama ortogonal parcial es la posible existencia de una vía que partiría del Puente de Alcántara y que podría corresponderse con el decumanus maximus. Quizá la localización del puente de San Martín (s. XIV) podría no ser aleatoria y sugerir la existencia de un puente antiguo en sus inmediaciones, ya que la prolongación del eje que partiría del primero en línea recta terminaría directamente en el segundo. Dicho recorrido ortogonal puede adivinarse, al menos en la zona central del peñón toledano, gracias a algunos restos arqueológicos documentados y conservados en el subsuelo de las actuales casas de la calle Gaitanas 2, Instituto o la calle de la Plata 9 y $11^{101}$ (Fig. 14 у 15-16, 19, 35).

En ambos casos, los restos se corresponden con opus cuadratum y formarían parte de la fachada de edificios públicos o privados de entidad. Recordemos además que en la calle de la Plata apareció el único togado conocido hasta hoy en Toletum, con unas medidas considerables $(170 \times 70 \times 30 \mathrm{~cm}) .{ }^{102}$ El descubrimiento de esta escultura en febrero de 2008, obligó a reconsiderar la verdadera entidad de Toletum y a plantear la posibilidad de la cercanía a su foro, lo que avalaría la posible correspondencia de este decumanus con el decumanus maximus.

101 Rosado Artalejo 2005.

102 García Sánchez De Pedro 2008; Nogales - Acuña 2013. 
Figura 14. Muro con dos hiladas de sillares de granito en la Calle Gaitanas 2.

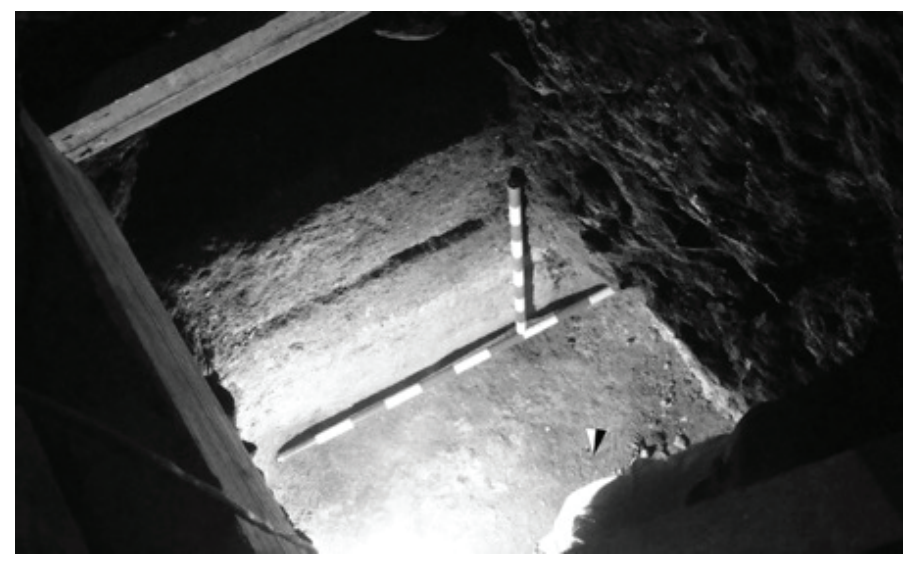

Otro elemento primordial a destacar es el descubrimiento en el año 2006 de cerca de $47 \mathrm{~m}$ de calle romana bajo los cimientos del Cristo de la Luz (Fig. 16), gracias a lo cual se ha podido trazar con certeza uno de los ejes principales que recorrerían la ciudad romana de noreste a suroeste. ${ }^{103}$ Con inicio en la puerta de Valmardón, que algunos autores consideran como substituta de la puerta romana original, ${ }^{104}$ esta vía cruzaría la ciudad hasta llegar al río, coincidiendo con la cloaca documentada en la Bajada del Barco, con una longitud aproximada de $915 \mathrm{~m}$ y una anchura en torno a los $6 \mathrm{~m}$. La evidente importancia de este eje permite plantear la posibilidad de que se correspondiera con el kardo maximus, ${ }^{105}$ que al cruzarse con el decumanus maximus propuesto anteriormente coincidiría con la ubicación del foro en el entorno de la calle de la Plata, asociado también al togado.

Además, que el entorno es importante lo confirma tanto el descubrimiento del togado como la existencia de complejos termales como los documentados en la calle Comercio 41 o la plaza de Amador de los Ríos. ${ }^{106}$ Las excavaciones de las termas localizadas en este último espacio, iniciadas en la década de los 80 del pasado siglo y finalizadas en la del 2000, han permitido identificar y contextualizar uno de los sectores de un complejo termal hasta el momento desconocido en la ciudad. ${ }^{107}$ Pese a lo arrasado de sus estructuras y subsuelo debido a las diferentes intervenciones, Sáinz Pascual ${ }^{108}$ considera que su construcción puede datar de finales del s. I d. C. y comienzos del II. Por otro lado, sus canalizaciones están orientadas con el sistema de abastecimiento de agua a la ciudad y posee una entidad lo suficientemente importante como para considerarlo como una de sus principales termas (Fig. 15-20,5). $\mathrm{Su}$ cercanía a este posible espacio foral puede dotarle de esa categoría. Además, por

103 Ruiz Taboada - Arribas Domínguez 2007; Ruiz Taboada 2014.

104 Rubio Rivera - TSIOLIS Karantasi 2004, 231.

105 RUBIO RIVERA - TSIOLIS KARANTASI 2004.

106 García Sánchez De Pedro 2005; Arribas Domínguez - Jurado JimÉnez 2005.

107 Sáinz Pascual 1996; Arribas Domínguez - Jurado JimÉnez 2005; Arribas Domínguez 2008.

108 SÁinz Pascual 1996, 43. 
recientes excavaciones en sus inmediaciones, sabemos que su superficie no se limitaba al sector excavado en el número 5 de la plaza de Amador de los Ríos, al haberse documentado restos de este complejo en edificios cercanos como el oratorio de Felipe Neri ${ }^{109} \mathrm{y}$, recientemente, en el número 6 de la calle Alfonso X, visibles en el sótano de una tienda de moda.

Figura 15. Plano de distribución de los principales hallazgos de la ciudad romana e hipótesis del desarrollo de la trama ortogonal. Fotografía aérea del Instituto Geográfico Nacional (PNOA). 1. Cantera del Cristo de la Luz; 2. Cantera San Lucas y María; 3. Puente de San Martín; 4. Puente de Alcántara; 5. Acueducto; 6. Castellum de Tornerías; 7. Castellum cueva de Hércules; 8. Cloaca principal Bajada del Barco; 9. Calle y cloaca del Cristo de la Luz; 10. Cloaca Valmardón; 11. Cloaca secundaria Bajada del Barco; 12. Cloaca de San Agustín; 13. Delegación de Hacienda; 14. Calle Lechuga 5; 15. Cloaca de la Sal; 16. Calle de la Plata 9 y 11; 17. Antiguo Mesón del Lino; 18. Alfileritos 24; 19. Gaitanas 2; 20. Termas de Amador de los Ríos; 21. Cloaca Juego de Pelota; 22. Torre puerta del Sol; 23. Circo; 24. Anfiteatro; 25. Ruinas adosadas al circo (desaparecidas); 26. Necrópolis de la Reconquista; 27. Edificio Lorenzana; 28. Menores 11;29. Comercio 41; 30. Madre de Dios; 31. Cuatro Calles; 32. Santa Isabel 18; 33. Necrópolis de Santa Leocadia; 34. Paseo de la Rosa; 35. Calle Instituto.

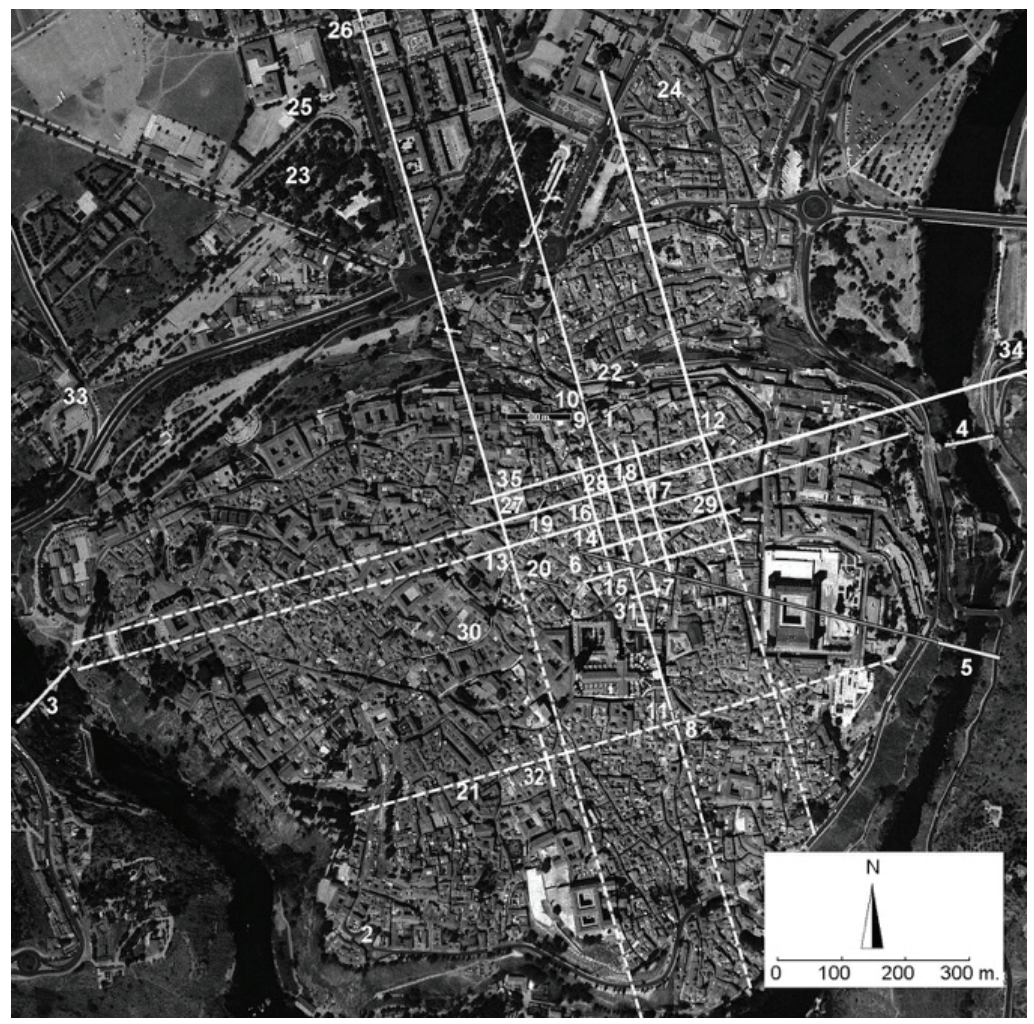

109 Agradecemos a Juan Manuel Rojas Rodríguez Malo la información aportada a este respecto. 
Figura 16. Calle romana del Cristo de la Luz en el momento de su excavación.

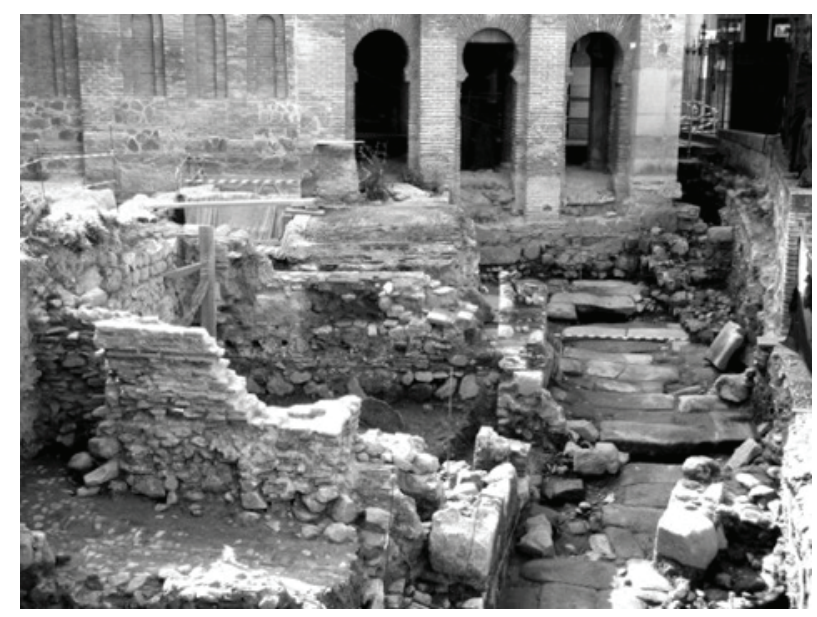

Otra hipótesis posible de cara a la identificación del foro, surgiría a raíz de barajar la posibilidad de que el kardo maximus fuera el alineado con la calzada exterior que da acceso a la ciudad (Via Sacra en la actual Avenida de la Reconquista). En este sentido, llama la atención que el eje imaginario resultante, coincide con un gran edificio actual (Fig. 15-27) que bien pudo ocupar la plaza de este hipotético foro, en el entorno también de la calle de la Plata y la Plaza Amador de los Ríos. Dicho edificio se corresponde con el Palacio Lorenzana de la Universidad de Castilla-La Mancha y casualmente orientado con el parcelario original romano que proponemos. En este sentido, sus 43 × 38 m de lado se asemejaría a las medidas del modelo de insulae de finales de la República e inicios del Imperio de 1 actus. De este modo, dos de sus fachadas se encontrarían alineadas con las supuestas calles romanas originales del entorno. De hecho, la documentación de un muro romano en su lado norte, calle Instituto, refrendaría esta hipótesis (Fig. 18-14). ${ }^{110} \mathrm{El}$ edificio fue diseñado por Ignacio Haan en plena ilustración, arrasando para ello una manzana medieval que contenía la antigua sede del Santo Oficio. Sin ningún dato documental que por el momento lo apoye, ${ }^{111}$ falta saber si el arquitecto pudo adaptar su diseño a unos hipotéticos restos antiguos que pudieran haber visto la luz en el momento de su derribo. Este edifico (Fig. 18-1) y sus inmediaciones merecen un estudio arqueológico en profundidad, ya que en la anexa iglesia de San Vicente (Fig. 18-13) se encuentra uno de los ábsides más antiguos y conocidos de la ciudad ${ }^{112}$ que conserva en su base el opus africanum de su fábrica original, con una orientación llamativamente similar a la que planteamos para esta zona. Este tipo de fábrica romana se documenta en Hispania principalmente entre los ss. I y II d.C. y la encontramos en foros del s. I como los de Caesaraugusta o Baelo Claudia. Precisamente en esta última ciudad dicha técnica

110 Rosado Artalejo 2005.

111 Agradecemos a Adolfo de Mingo la información a este respecto.

112 Porres Martín-Cleto 2002. 
constructiva se observa en la basílica, edificio cuya planta podría asemejarse con el ábside de la iglesia de San Vicente.

Continuando con el análisis de la trama urbana, la existencia de un cierto modelo ortogonal para la zona más elevada de la ciudad se ve reforzada por la documentación arqueológica de alineaciones de muros y sectores de cloaca documentados en ella (Fig. 18). Los datos que a continuación analizamos apuntan a la existencia de, al menos, un barrio con insulae de planta rectangular de $43 \times 33 \mathrm{~m}$ aproximadamente y una anchura de calle de $3 \mathrm{~m}$. La base de esta hipótesis para este sector urbano reside en el hallazgo tanto de muros alineados como de intersección de calles y calles propiamente dichas recorridas por cloacas. Posiblemente, el más representativo es el documentado en la calle de la Lechuga 5 (Fig. 17-1 y 18-8). Fosilizado en uno de los muros de una edificación medieval, se documentó una calle romana de $3 \mathrm{~m}$ de ancho flanqueada por sendas esquinas pertenecientes a dos insulae, espacio sobre el que se articularía el muestrario de restos arqueológicos repartidos por este barrio. ${ }^{113}$ Intersecciones similares las tenemos en la calle Santa Isabel 18 (Fig. 15-32), descubierta gracias a una reciente intervención ${ }^{114} \mathrm{y}$ también pueden identificarse fosilizadas en el callejero de la ciudad. Para este último caso, nos encontramos con topónimos como las Cuatro Calles, que da nombre a un conocido espacio toledano. De este lugar constan noticias ya en el s. XIV, ${ }^{115}$ y se corresponde con un ensanche producido por una confluencia de calles frente a la puerta del Reloj de la catedral. Existen dos circunstancias que hacen este topónimo especial. De un lado, las calles que derivan en este ensanche no son cuatro sino cinco, lo que sugiere un cambio en el parcelario y la distribución viaria que hizo que se añadiera una calle en época medieval, manteniendo la antigua denominación. De otro, el lugar coincide con la confluencia imaginaria de un kardo y un decumanus (Fig. 15-31), lo que sugiere que el origen de este topónimo provenga de la confluencia de las cuatro calles que forman el cruce de las correspondientes insulae.

Además de los muros ya comentados, existen otros que apuntan a la existencia de este trazado ortogonal. Entre ellos se encuentran, aparte de los ya citados muros de sillares de la calle Plata 9 y 11, los muros de estancias de una de estas insulae descubiertas en la excavación del desaparecido mesón del Lino, el resto de muro de hormigón de la calle Alfileritos $24^{116}$ o el muro de sillares de la calle Menores 11 (Fig. $18-2,4,6,7)$.

Con respecto a los tramos de cloaca, la mayoría han sido reutilizados en épocas posteriores, destacando la readaptación de los cimientos de un muro de fachada de una casa medieval a una cloaca en la plaza del Juego de Pelota ${ }^{117}$ o la propia Bajada

113 Ruiz Taboada 2012, 46. Recientemente, José María Gutiérrez ha puesto en marcha un blog en la web del Consorcio de la Ciudad de Toledo que, entre otras cosas, describe y ubica alguno de los restos romanos inéditos mencionados en este artículo.

114 Dirigida por Arturo Ruiz Taboada y Sandra Azcárraga Cámara en el año 2014 con autorización de la Viceconsejería de Cultura de la Junta de Comunidades de Castilla La Mancha.

115 Porres Martín-Cleto 2002, 462.

116 Passini et alii 1994; Maquedano Carrasco - Barrio Aldea 1996; García Sánchez De Pedro 2008 ; Ruiz TABOADA 2012.

117 Ruiz TABOAdA - Mencía 2005. 
del Barco (Fig. 17). Pese a los siglos transcurridos, la mayoría de estas cloacas han permanecido en uso, al conservarse la mayoría de las calles asociadas a ellas. Ejemplo documental de estas reutilizaciones lo tenemos en la plaza Mayor, donde con motivo de la construcción del nuevo Hospital del Rey, las fuentes históricas mencionan la existencia de una cloaca romana en la calle que discurría entre la catedral y el antiguo hospital. Este canal comunicaba las Cuatro Calles con la calle de la Tripería y la Bajada del Barco (Fig. 15). Una vez terminado el nuevo hospital y clausuradas estas calles, la cloaca, como ocurre en otras zonas de la ciudad, debió de ser integrada a las nuevas construcciones y utilizada como sumidero de éstas. ${ }^{118}$

Figura 17. Intersección localizada en el $n^{\circ} 5$ de la calle Lechuga (1) y sección de las cloacas del tramo final de Valmardón (2), Cristo de la Luz (3), Bajada del Barco (4) y diversos tramos del Juego de Pelota (5).

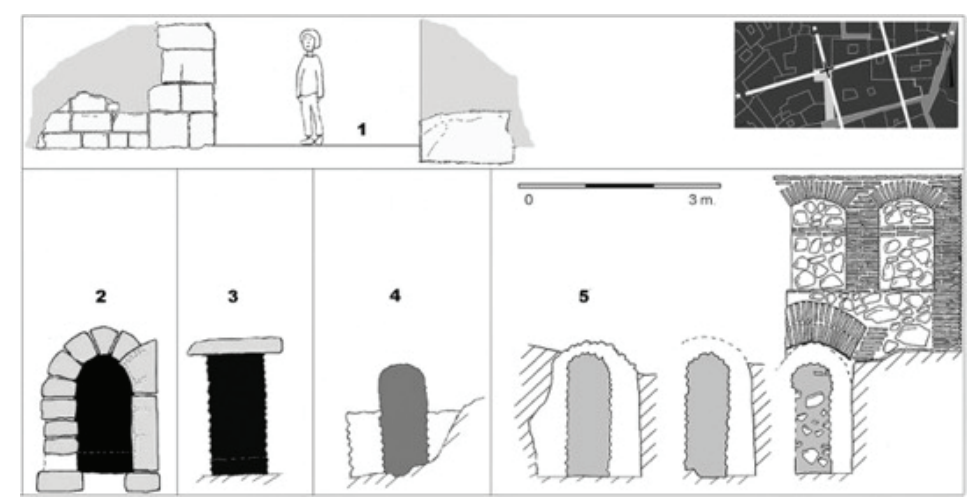

Con respecto a la tipología de estas cloacas, puede existir gran diversidad de tipos. El primero se encuentra representado en la canalización del Cristo de la Luz, adintelada, reaprovechando las losas de la calle que discurre en su superficie como cubierta y con las paredes de opus caementicium (Fig. 17-3). El segundo, documentado en su terminación bajo la puerta de Valmardón, con una cubierta abovedada construida íntegramente con sillares de granito (Fig. 17-2). Esta consistencia estructural responde a la necesidad de servir de cimiento a un tramo de muralla. ${ }^{119}$ Pero el tipo de cloaca más común es la realizada en opus caementicium y con cubierta abovedada. Dicha estructura se ha documentado en lugares tan distantes como los citados sótanos de la Delegación de Hacienda, la calle de la Sal, Juego de Pelota, el entorno del antiguo colegio de Infantes o el ya comentado de la Bajada del Barco (Fig. 15 y 17-4, 5).

Este complejo hidráulico se completa con un sistema de abastecimiento de agua de la ciudad mediante un acueducto como su construcción más visible. Tanto la orientación del mismo, como el sistema de canales y la red de sifones repartidos por la urbe, permiten interpretar en el contexto urbano tanto su planificación como su desarrollo (Fig. 15-5, 6, 7, 13). Los cuatro sifones conocidos hasta el momento, se encuentran

118 Ruiz TABOAda 2012.

119 Ruiz Taboada 2014. 
en línea con la traza conservada del acueducto y se localizan en las zonas elevadas de la ciudad. Su situación está en relación con la distribución del agua al resto de la urbe. El primero de ellos se ha conservado como cimentación de la mezquita de Tornerías y el segundo se localiza en las cuevas de Hércules, mientras que los dos restantes se localizan bajo los sótanos de Hacienda y el convento de San Clemente. ${ }^{120}$

Figura 18. Detalle del posible trazado ortogonal en el sector central de Toletum. 1. Edificio Lorenzana; 2. Callejón de Menores 11; 3. Calle Alfileritos 24; 4. Delegación de Hacienda; 5. Calle Gaitanas 2; 6. Calle de la Plata 9 y 11; 7. Antiguo bar Lino; 8 Calle Lechuga 5; 9. Comercio 41; 10. Cloaca calle de la Sal; 11 . Cloaca y calle del Cristo de la Luz; 12. Cloaca de la calle San Agustín; 13. Ábside de San Vicente; 14. Calle Instituto.

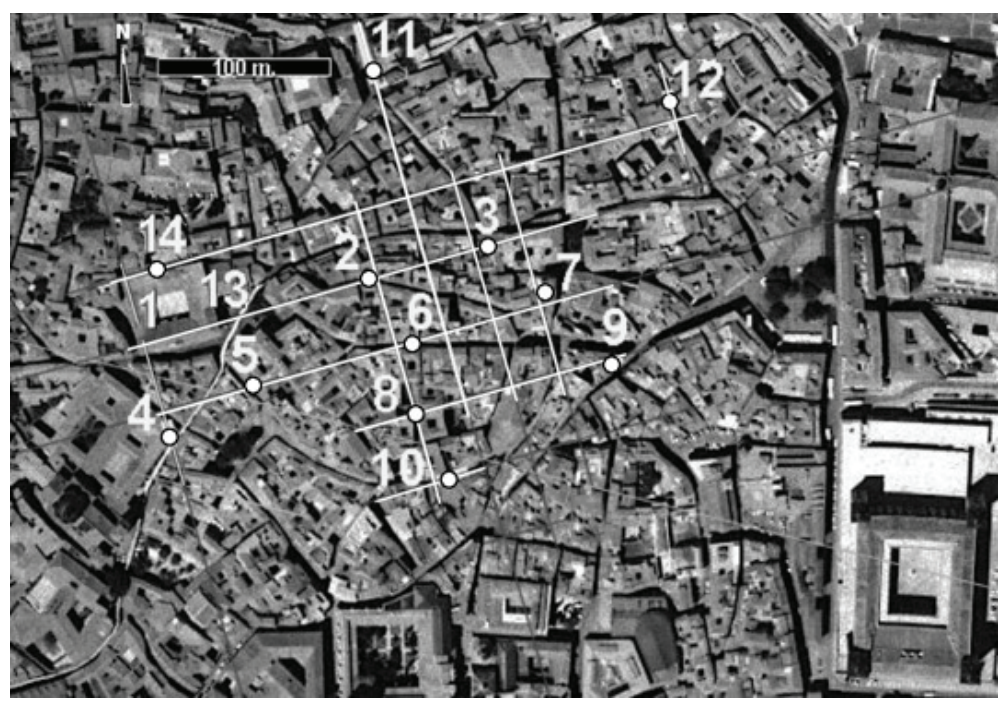

Para terminar este análisis de la trama urbana de Toletum debemos tratar de explicar cómo se podrían habilitar las diferentes elevaciones existentes en este sector central del peñón toledano, para posibilitar el diseño de la posible trama ortogonal parcial que proponemos. En este sentido, el descubrimiento de una cantera en el entorno de la iglesia del Cristo de la Luz da idea del planeamiento previo al diseño urbanístico del Toletum. Los $70 \mathrm{~m}^{2}$ de superficie excavada muestran un sistema de extracción de roca por sectores, que aún conservan muescas y entalles relacionados con la manipulación de las piedras ${ }^{121}$ (Fig. 15-3). Además de su funcionalidad extractiva, la excavación de la roca en este sector de la ciudad puede estar en relación con el allanamiento general del terreno sobre el que se van a organizar los diferentes ejes viarios que van a dar comunicación con la zona alta de la ciudad. Por desgracia, es difícil establecer la fecha de explotación de esta cantera por estar su superficie

120 Tsiolis Karantasi 2013; Rosado Artalejo 2005, 228.

121 Ruiz Taboada 2014, 18. 
alterada, aunque el abandono de la ocupación del entorno se ha fijado entre los ss. III y V d.C. ${ }^{122}$

En el resto de la ciudad se han documentado similares tratamientos de terreno, como en las obras de excavación para la construcción de un polideportivo en el colegio Lucas y María en 2004 (Fig. 15-2), con un rebaje de la roca similar al del Cristo de la Luz, con excavación de la roca empleando un sistema de plataformas de planta cuadrangular. Un caso similar lo encontramos en el convento de Madre de Dios, con la talla de la roca para habilitar un sistema de plataformas de nivelación del terreno ${ }^{123}$ (Fig. 15-30). Mientras que el área excavada de la primera ascendía a $80 \mathrm{~m}^{2}$, la segunda se documentó en una superficie aproximada de $800 \mathrm{~m}^{2}$. La datación relativa de esta última sitúa al conjunto entre finales del s. I a.C. y mediados del II d.C.

Este tipo de allanamiento se encuentra documentado en numerosas ciudades hispanas como Clunia o Baelo Claudia cuya topografía no permitió desarrollar una trama ortogonal convencional y obligo a adaptarse a cada lugar, con el desarrollo de trazados urbanos regulares a pesar de los marcados desniveles. ${ }^{124}$ Dentro de la Carpetania merece la pena destacar el ejemplo de la ciudad romana de la Dehesa de la Oliva, edificada en lo alto de un cerro y donde destaca la construcción de un amplio espacio porticado, aprovechando la visera de un abrigo natural. ${ }^{125}$ En Toledo, además de las canteras antes descritas, algunas de las calles de la ciudad se diseñan cajeando la roca madre, práctica que debió ser habitual en época romana y que debió continuar durante la Edad Media. No obstante, pese a la existencia de estas canteras, no todo el material empleado en Toletum proviene de la extracción de piedra local. Un reciente trabajo ha demostrado el complejo comercio y transporte de piedra existente en la ciudad en esa época, que llegó a importar piedra y mármol de canteras alejadas a cientos de kilómetros de la urbe. ${ }^{126}$

\section{Conclusiones}

La excavación de la Bajada del Barco junto a la contextualización de los hallazgos más representativos inventariados en Toletum, muchos de ellos mencionados reiteradamente en la bibliografía, permite plantear una visión alternativa a la tradicional empleada para explicar el desarrollo urbanístico de la ciudad antigua. En este sentido, uno de los principales inconvenientes ha sido tratar de racionalizar la propuesta de un diseño parcial ortogonal sobre la abrupta topografía en la que se asentaba parte del oppidum carpetano. Para ello, se han analizado también las diferentes canteras documentadas en el interior de la ciudad, en un intento de explicar un complejo proceso de urbanización que implica la nivelación del terreno en aquellas zonas que lo necesitan,

122 Arribas Domínguez 2006, 106.

123 Rojas RodríGuez Malo et alii 2007, 290.

124 Rubio Rivera 1997, 363; EAD. 2005, 139.

125 Vigil-Escalera 2012, 254.

126 Mesa Garate 2013. 
aprovechando la extracción de la roca como cantera para la construcción de la ciudad $\mathrm{y}$, en última instancia, aprovechando funcionalmente el allanamiento generado.

El resultado ha sido la propuesta de identificación en planta de un barrio ortogonal en el sector más elevado de la ciudad, compuesto de insulae de en torno a 43 x 33 m, en el eje iglesia del Cristo de la Luz/Catedral de Santa María y su posible extensión en la zona central de la urbe y quizá en otras al sur. Además, se apuntan las claves para una localización futura de espacios públicos como el foro y las termas, que pudieron ubicarse en el eje palacio Lorenzana-plaza de Zocodover. El diseño urbano propuesto permite articular zonas de la ciudad actual de gran potencialidad arqueológica romana, al tiempo que contextualiza espacios que conservan fosilizadas las trazas antiguas.

Fuera del sector central analizado en profundidad, es más difícil rastrear la ortogonalidad propuesta, lo que mostraría la heterogeneidad de la trama urbana para adaptarse al terreno o incluso su correspondencia con distintos momentos en los que pudieron existir diseños de ciudad con otra orientación, casos por otra parte, comunes en otras ciudades romanas de similares características.

Finalmente, la excavación y estudio del material hallado en las cloacas de la Bajada del Barco, ha permitido confirmar la extensión del urbanismo romano en el peñón toledano desde al menos el final de la época Julio-Claudia, además de evidenciar el continuo crecimiento de la ciudad con la construcción de cloacas secundarias en un momento avanzado del s. I d.C. y su ulterior abandono. Así, según las fuentes, Toletum ya se hallaba ocupada al menos desde principios del s. II a.C., aunque arqueológicamente los escasos restos materiales (al menos los publicados) impiden contrastar este hecho, destacando únicamente los dos fragmentos de barniz negro itálico localizados en la excavación del Circo. En este sentido, el as de Kese de la Bajada del Barco, aunque descontextualizado, nos sitúa en la primera época de la ocupación romana, en torno a finales del s. II a.C. Con respecto al Alto Imperio, los materiales más antiguos asociados a elementos estructurales se fechan a partir del tercer cuarto del s. I d.C., aunque se conocen diversos contextos de la primera mitad del s. I d.C. tanto en el peñón toledano, Puerta del Sol o en la Calle Real 4, 6 y 8, como en el entorno del circo en niveles anteriores a su fundación. ${ }^{127} \mathrm{El}$ hallazgo de materiales de la segunda mitad del s. I d.C., como son la mayoría de los documentados en la Bajada del Barco, es mucho más numeroso en Toletum, destacando su reciente documentación en la Vega Baja, asociados a un sondeo de extracción de áridos. ${ }^{128}$ Con respecto a las cloacas, por la Bajada del Barco sabemos que en época de Diocleciano se inicia el proceso de abandono de las mismas (entre finales del s. III y principios del IV d.C.) alternando esta pérdida de uso de alguna de ellas con la conservación y reutilización de, al menos, las principales en épocas siguientes.

A pesar del evidente avance en la investigación en los últimos años, todos los datos expuestos evidencian la ausencia de un sistema de documentación de restos arqueológicos en Toledo, a modo de plan director, que permita la correcta contextualización

127 Rubio Rivera - Tsiolis Karantasi 2004; FernÁndez Del Cerro 2005; Sánchez Palencia et alii 1988.

128 PEÑA et alii 2009, 159. 
de los hallazgos existentes y de los que se producen a diario. Por desgracia, que no se haya hecho hasta ahora hace que cualquier hipótesis de trabajo se encuentre siempre en constante revisión.

\section{Bibliografía}

Abascal Palazón, J. M. - AlföLdy, G. (2015): Inscripciones romanas de la provincia de Toledo (siglos I-III), (=Bibliotheca Archaeologica Hispana 42), Madrid.

Abascal Palazón, J. M. - González-Conde, M. P. (2007): “Carpetania: argumentos para una definición del territorio en época romana”, [en] A. Dávila (ed.), Estudios sobre la Edad del Hierro en la Carpetania (=Zona Arqueológica 10), Alcalá de Henares, vol. I, 290-301.

AlCocer, P. (1554): Historia o descripción de la imperial ciudad de Toledo, Toledo.

Almagro-Gorbea, M. (1994): "Urbanismo de la Hispania céltica. Castros y oppida del centro y occidente de la Península Ibérica", Complutum Extra 4, 13-75.

Almagro-Gorbea, M. - Dávila, A. F. (1995): "El área superficial de los oppida en la Hispania céltica", Complutum 6, 209-233.

Almagro-Gorbea, M. - Lorrio Alvarado, A. J. (2006-2007): "De Sego a Augusto: los orígenes celtibéricos de Segobriga", BSAA 72-73, 143-181.

Alvar Ezquerra, J. - Mangas Manjarrés, J. (1990): "La municipalización de Carpetania", [en] 'Toledo y Carpetania en Edad Antigua: Simposio celebrado en el Colegio Universitario de Toledo, 6 al 8 de noviembre de 1986, Toledo.

ANDREU, J. (2008): "Municipalización y vida municipal en las comunidades romanas de la Meseta sur", [en] G. Carrasco (coord.), La romanización del territorio de Castilla la Mancha, Cuenca, 225-260.

Aranda Alonso, F. - Carrobles Santos, J. - Isabel Sánchez, J. L. (1997): El sistema hidráulico romano de abastecimiento a Toledo, Toledo.

Arenillas Parra, M. - Barahona Oviedo, M. - Gutiérrez Argul, F. - Cauce Cañizares C. (2009): El abastecimiento de agua a Toledo en época romana, Madrid.

Arribas Domínguez, R.

(2006): "El espacio urbano anterior a la construcción de la mezquita del cristo de la Luz: Evidencias arqueológicas", Los Monográficos del Consorcio de la Ciudad de Toledo 5, 7398.

(2008): "Nuevas aportaciones para el estudio del uso y distribución del agua en la ciudad romana de Toletvm", [en] Actas del IV congreso de obras públicas en la ciudad romana, Madrid, 263-273.

ARribas Domínguez, R. - JuRAdo JimÉnez, F. (2005): "La intervención en las termas romanas de la plaza de Amador de los Ríos 5", Los Monográficos del Consorcio de la Ciudad de Toledo 1, 17-54.

AzCÁrRaga Cámara, S.

(2014): "Nuevos datos sobre la romanización de la Carpetania centro-septentrional", [en] I Simposio sobre los Carpetanos: Arqueología e Historia de un pueblo de la Edad del Hierro, Alcalá de Henares, 435-445. 
(2015): El ocaso de un pueblo. La Carpetania centro-septentrional entre la Segunda Edad del Hierro y la época romana (ss. III a.C.- I d.C.): El valle bajo del Henares (=Zona Arqueológica 18), Madrid.

Azcárraga Cámara, S. - Ruiz Taboada, A. (2012-2013): "Los orígenes de Complutum: el descubrimiento de la planta de la ciudad romana de San Juan del Viso (Villalbilla, Madrid)", Anales de Arqueología Cordobesa 23-24, 95-116.

Barahona Oviedo, M. - Arenillas Parra, M. - Rojas RodríGuez-Malo, J. M. (2014): “En torno a la red romana de abastecimiento de agua a Toledo: Excavaciones en los terrenos de la academia militar de infantería", Zephyrus 74, 203-223 (http://dx.doi.org/10.14201/ zephyrus201474203223).

Barrio Aldea, C. - Maquedano Carrasco, B. (1996): "Huerto del convento de Carmelitas Descalzos", [en] Toledo Arqueología en la ciudad, Toledo, 269-273.

Blanco García, F. J. - JuAn Tovar, L. C. (1996): “Acerca de M.C.R. y otros alfareros hispánicos: Marcas y grafitos en Terra Sigillata Hispánica de Cauca (Coca, Segovia)”, BSEAA 36, 147-155.

Blanco García, F. J. - Pérez González, C. - Reyes Hernando, O. V. (2012-2013): “Campaña de excavación arqueológica de 1999 en Cauca (Coca, Segovia). La secuencia estratigráfica", Oppidum 8-9, 29-144.

Blázquez, J. M. (2012): “Toledo romana en la investigación actual”, [en] Carrasco Serrano (coord.), 2012, 57-85.

CAnto, A. (2001): "Fuentes árabes para la Mérida Romana", [en] F. Valdés - A. Velázquez (eds.), La islamización de la Extremadura Romana (=Cuadernos Emeritenses 17), Mérida, 9-86.

CAPAlvo, A. (1996): Celtiberia. Un estudio de fuentes literarias antiguas, Zaragoza.

Carrasco Serrano, G. (1996-1997): "Sobre el proceso de romanización del territorio provincial de Toledo", [en] Actas Congrés d'Homenatge al Dr. P. De Palol II, Gerona, 745754.

Carrasco Serrano, G. (CoOrd.), (2012): La ciudad romana en Castilla-La Mancha (=Colección Estudios 134), Cuenca.

Carrobles Santos, J. (2001): El teatro romano de Toledo: Una propuesta de identificación, Toledo.

DíAz Ariño, B. (2008): Epigrafía Latina Republicana de Hispania (=Instrumenta 26), Barcelona.

Domergue, C. (1971) El Cerro del Plomo, Mina El Centenillo, Jaén (=Noticiario Arqueológico Hispánico XVI), Madrid.

FARIÑa ToJo, J. (1996): Influencia del medio físico en el origen y evolución de la trama urbana de la ciudad de Toledo, Madrid.

FernáNDEZ DEL CERro, J. (2005): "Un conjunto de materiales de época Altoimperial en la calle Real 4, 6 y 8", Los Monográficos del Consorcio de la Ciudad de Toledo 5, 77-82.

Fernández Del Cerro, J. - Barrio Aldea, C. (2002): “Topografía del Toletum prerromano", Bolskan 19, 359-368.

Fernández OchoA, C. (2002): Las Termas romanas de Campo Valdés, Gijón.

García SÁnchez De Pedro, J.

(1996): "Paseo de la Basílica, 92", [en] Toledo Arqueología en la ciudad, Toledo, 143-157. 
(2005): “Comercio 41: Restos de un hipocaustum", Los Monográficos del Consorcio de la Ciudad de Toledo 1, 185-190.

(2008): "Rehabilitación del inmueble calle de la Plata 9 y 11 (Toledo)", Herencia Recibida 08,38 .

García y Bellido, A.

(1977): La España del siglo I de nuestra Era, Madrid.

(2004): "La Carpetania. El mundo romano en Madrid y sus contornos", EPAM 13, 31-43 (conferencia leída en Madrid el 20 de abril de 1961).

GonzÁlez-Conde, M. P.

(1985): "Promoción jurídica y organización municipal de Complutum en el Alto Imperio", Lucentum 4, 133-146.

(1987): Romanidad e indigenismo en Carpetania, Alicante.

Gozalbes Cravioto, E. (2004): "Estudios recientes sobre la romanización en la Meseta Meridional", $H A 28,87-116$.

Huici Miranda, A. (1969): al-Mann Bil-Imama (=Textos Medievales 24), Valencia.

IsINGS, C. (1957): Roman Glass from dated finds, Groningen-Djakarta.

JimÉNEz ÁvilA, F. J. (1989-1990): "Notas sobre la minería romano-republicana bajoextremeña: Las explotaciones de plomo de la sierra de Hornachos (Badajoz)", Anas 213, 123-134.

JuAn Tovar, L. C. (2000): "La Terra Sigillata de Quintanilla de la Cueza", [en] M. A. García Guinea (dir.), La villa romana de Quintanilla de la Cueza (Palencia). Memoria de las excavaciones 1970-1981, Palencia, 45-122

León Alonso, M. P. - Venturada, A. - López, I. - Márquez, C. - Bermúdez, J. M. (1996): "Análisis arqueológico de la Corduba romana: resultados e hipótesis de la investigación", [en] M. P. León (coord.), Coloquio Internacional Colonia Patricia Corduba (1993), Córdoba, 87-118.

MANGAS MANJARRÉs, J.

(1995): De Aníbal al emperador Augusto. Hispania durante la República romana, Madrid. (2012): "Ciudades romanas del ámbito de la provincia de Toledo", [en] Carrasco Serrano (coord.), 2012, 201-224.

Maquedano Carrasco, B. - Barrio Aldea, C. (1996): “Callejón de Menores 11”, [en] Toledo Arqueología en la ciudad, Toledo, 305-308.

MARTín EsCORZA, C. (2008) "Dimensiones y orientaciones de anfiteatros y circos romanos en el imperio romano", Kalakorikos 13, 185-193.

Martínez, J. M. - Blázquez, J. M. (1982): Mosaicos romanos de la Real Academia de la Historia, Ciudad Real, Toledo, Madrid y Cuenca (=Corpus de mosaicos de España. Fasciculo V), Madrid.

Mateos Cruz, P. (2001): “Augusta Emerita. La investigación arqueológica en una ciudad de época romana”, AEspA 74, 183-208 (http://dx.doi.org/10.3989/aespa.2001.v74.153).

Mena muÑoz, P. (1988): "La época republicana en Castilla-La Mancha: inicios de la romanización”, I Congreso de Historia de Castilla-La Mancha. Tomo IV, 25-51. Toledo.

Mesa Garate, A. (2013): Los marmora de Toletum: Estudio de los granitos y calizas del centro peninsular empleados en la ciudad romana y tardoantigua de Toledo, Tesis Doctoral, Universidad de Rovira y Virgili, Tarragona. 
MezQuíriz, M. A.

(1961): Terra Sigillata Hispánica, Valencia.

(1983): “Tipología de la Terra Sigillata Hispánica”, BMAN I/2, 123-131.

Montero Vallejo, M. (1988): “Toledo, de la acrópolis a la ciudad: orígenes, constantes y morfología”, [en] Toledo, ¿ciudad viva?, ¿ciudad muerta?, Toledo, 215-239.

Nogales, T. - AcuÑA, P. (2013): "Estatua romana togada del forum de Toletum", [en] F. Acuña - R. Casal - S. González (eds.), Escultura romana en Hispania VII. Homenaje al Prof. Dr. Alberto Balil, Santiago de Compostela, 221-240.

Passini, J. - MolénAt, J. P. - SÁnchez-Chiquito de la Rosa, S. (1994): "El barrio de Santa Justa y el mesón del Lino al final de la Edad Media”, Anales Toledanos 31, 65-121.

Palol, P. (1972): "Una tumba romana de Toledo y los frenos de caballo hispanorromanos del Bajo Imperio", Pyrenae 8, 133-146.

Palomero Plaza, S. (2001): "Una hipótesis de reconstrucción de la red viaria romana en la Submeseta Sur según el It. de Antonino (Vías 24, 25, 29, 30 y 31)”, [en] J. Carrobles Santos - A. Ruiz Taboada (coords.), II Congreso de Arqueología de la Provincia de Toledo, Toledo, vol. I, 303-332.

Peña Cervantes, Y. - García-Entero, V. - Gómez Rojo, J. (2009): “Aportaciones al conocimiento de la evolución histórica de la Vega Baja de Toledo. Estudio preliminar de la excavación de la parcela R-3", ETF Prehistoria y Arqueología 2, 157-175 (http://dx.doi. org/10.5944/etfi.2.2009.1955).

Pisa, F. (1605): Descripción de la Imperial ciudad de Toledo, Toledo.

Plácido, D. - Mangas, J. - Fernández-Miranda, M. (1992): “Toletum”, D. Arch. 10, 263 275.

Porres Martín-Cleto, J.

(1989): Planos de Toledo, Toledo.

(1992): "En torno a las murallas de Toledo", Castelum 1, 33-62.

(2002): Historia de las calles de Toledo, Toledo.

RAMÓn, S. (1857): Toledo en la mano, Toledo, vol. II.

Ramos SÁinz, M. L. (2008): “Terracotas y elementos de coroplastia”, [en] D. Bernal - A. Ribera (coords.), Cerámicas hispanorromanas: un estado de la cuestión, Cádiz, 775-786.

Rey Pastor, A. (1932): El circo romano de Toledo, Toledo.

Rojas Rodríguez Malo, J. M. (1996): "Paseo de la Rosa, 76 (La piscina romana de Cabrahigos)", [en] Toledo Arqueología en la ciudad, Toledo, 67-81.

RojasRodríguezMalo,J.M.-GómezLaguna,A.-Perera Rodríguez, J.-PÉRezLóPezTriVIÑo, J. - GARrido Resino, G. (2007): "El convento Madre de Dios. Evolución histórica de una manzana de Toledo a través de la arqueología", [en] J. Passini - R. Izquierdo (coords.), La ciudad medieval de Toledo: Historia, arqueología y rehabilitación de la casa. El edificio Madre de Dios: Universidad de Castilla-La Mancha, Toledo, 281-319.

Román Martínez, P. (1942): "Restos de construcción romana del puente de Alcántara”, Boletín de la Real Academia de Bellas Artes y Ciencias Históricas de Toledo 58, 3-21.

ROMERo CARNICERo, M. V.

(1984): “Sobre ciertas producciones precoces de sigillata en la Península Ibérica: los ceramistas Asiaticus y Maternus y nuevos vasos de M. C. R.”, BSAA 50, 91-112. 
(1984a): "En torno a ciertas producciones precoces de sigillata en la Península Ibérica: los vasos firmados M. C. R.”, [en] I Symposim de Arqueología Soriana, Soria, 343-359. (1985): Numancia I. La terra sigillata (=EAE 146), Madrid.

Rosado Artalejo, J. A. (2005): "Planimetría de los restos romanos de Toletum", Los Monográficos del Consorcio de la Ciudad de Toledo 1, 227-229.

Rosado Tejerizo, E. (2011): "El circo romano de Toledo. Evolución histórica de un Bien de Interés Cultural de una ciudad Patrimonio de la Humanidad", [en] Proyectos urbanos y arqueológicos en las Ciudades Patrimonio de la Humanidad de España, Alcalá de Henares, 195-214.

RUBio RIVERA, R.

(1997): "Sobre la configuración urbana de la ciudad romana de Toledo", [en] R. Villena Espinosa (coord.), Ensayos humanisticos. Homenaje al profesor Luis Lorente Toledo, Toledo, 361-377.

(2005): “Toledo romano: Balance y nuevas perspectivas en la investigación”, Los Monográficos del Consorcio de la Ciudad de Toledo 1, 135-142.

(2010): "El circo romano de Toledo y la Vega Baja en época romana", [en] La Vega Baja. Investigación, documentación y hallazgos, Toledo, 34-54.

(2013): "Los orígenes de Ercávica y su municipalización en el contexto de la romanización de la Celtiberia meridional", Vinculos de Historia 2, 169-183.

Rubio Rivera, R. - Tsiolis Karantasi, V. (2004): "El primer recinto amurallado de Toledo", [en] Monumentos Restaurados. Las Murallas de Toledo, Madrid, 225-250.

Rubio Rivera, R. - Valero Tévar, M. A. - Molina Cañadas, M. - Arcos Domínguez, M. C. (2010): "La villa romana de la fábrica de Armas (Toledo)", [en] La Vega Baja. Investigación, documentación y hallazgos, Toledo, 58-82.

Ruiz TABOADA, A.

(2012): Arqueología civil y religiosa: Toledo (s. X-XVIII), Madrid.

(2014): La iglesia del Cristo de la Luz, antigua mezquita de Toledo. Guía arqueológica, Toledo.

Ruiz Taboada, A. - Arribas Domínguez, R. (2007): "El descubrimiento de una vía monumental romana en Toledo", El Nuevo Miliario 4, 5-13.

Ruiz Taboada, A. - Azcárraga CÁmara, S. (2014): “A picture is worth a thousand words: The first Complutum photograph plan view (Villalbilla, Madrid)", Assemblage 13, 14-25.

Ruiz Taboada, A. - Mencía, C. (2005): "La reutilización de estructuras hidráulicas en Toledo: La cloaca romana del Juego de Pelota”, Los Monográficos del Consorcio de la Ciudad de Toledo 1, 119-133.

SÁenz Preciado, J. C. (2000): "Las primeras producciones de Sigillata Hispánica. Asiaticus y MCR, dos alfareros precoces en Bilbilis (Calatayud, Zaragoza)", Salduie 1, 283-294.

SÁinz Pascual, M. J. (1996): "Plaza Amador de los Ríos 5”, [en] Toledo Arqueología en la ciudad, Toledo, 41-43.

Sánchez-Moreno, E. - Gómez-Pantoja, J. L. (2008): Protohistoria y antigüedad en la Península Ibérica II: La iberia prerromana y la romanidad, Madrid.

SÁnchez Palencia, J. - SÁinz Pascual, M. J.

(1988): El circo romano de Toledo: Estratigrafia y arquitectura. Toledo.

(2002): "El circo de Toletum", [en] T. Nogales - J. Sánchez Palencia (eds.), El Circo en Hispania Romana, Mérida, 97-115. 
SCHATTNER, T.

(2003): Munigua. Cuarenta años de investigaciones, Sevilla.

(2009): "Römische Spolien in Toledo", [en] T. Schattner - F. Valdés Fernández (hrsg.), Spolien im Umkreis der Macht. Spolia en el entorno del poder, Madrid, 91-150.

STYlow, A. (1990): “Apuntes sobre el urbanismo de la Corduba romana”, [en] W. Trillmich P. Zanker (coords.), Stadtbild und Ideologie: die Monumentalisierung hispanischer Städte zwischen Republik und Kaiserzeit (Kolloquium in Madrid vom 19. bis 23. Oktober 1987), Madrid, 259-282.

Tsiolis Karantasi, V. (2013): "La cueva de Hércules en la construcción ideológica de Toledo", [en] R. Cid López - E. García Fernández (eds.), Debita verba. Estudios en homenaje al profesor Julio Mangas Manjarrés, Oviedo, vol. 2, 735-748.

Velázquez Jiménez, A. (1998): “Colonia Augusta Emerita”, [en] Hispania: el legado de Roma en el año de Trajano. La Lonja-Zaragoza (septiembre-noviembre de 1998), Madrid, 397-404.

Vigil-Escalera Guirado, A. (2012): "El asentamiento encastillado altomedieval de la Dehesa de la Oliva (Patones, Madrid)", [en] J. A. Quirós Castillo - J. M. Tejado Sebastián (coords.), Los castillos altomedievales en el noroeste de la Península Ibérica, Bilbao, 239262.

Zozaya Stabel-Hansen, A. - Rojas Rodríguez Malo, J. M. - Villa González, R. (2005): "El Alcázar Medieval de Toledo", [en] Espacios fortificados en la Provincia de Toledo, Toledo, 201-230. 